\title{
MODELING ELECTRO-RHEOLOGICAL MATERIALS THROUGH MIXTURE THEORY
}

\author{
K. R. RAJAGOPAL and R. C. YALAMANCHILI \\ Department of Mechanical Engineering, University of Pittsburgh, Pittsburgh, PA 15261, U.S.A.
}

\section{A. S. WINEMAN}

Department of Mechanical Engineering and Applied Mechanics, University of Michigan, Ann Arbor, MI 48109, U.S.A.

(Communicated by C. G. SPEZIALE)

\begin{abstract}
Electro-rheological materials are suspensions of particles in non-conducting fluids, and all models that have been developed to date describe their behavior by treating them as a homogenized single continuum, and ignoring the multicomponent structure of the material. The theory of interacting continua is ideally suited for modeling such mixtures and in this paper we present a simple theory which takes into account the distribution of the particles in the fluid, the applied electric field, and the relative motion of the two constituents. To illustrate the utility of such a theory we study the flow of an electro-rheological material between two parallel plates under the application of an electrical field normal to the plates.
\end{abstract}

\section{INTRODUCTION}

Electro-rheological materials are suspensions of non-conducting particulate media in nonconducting fluids. Properties like viscosity of the suspension change significantly on the application of an electric field. This phenomenon was observed over three decades ago by Winslow [1]. Such behavior can be gainfully employed in a wide range of technological applications from the design of clutches, brakes, shock absorbers and journal bearings to a plethora of applications in hydraulics. Much of the effort that has been expended in recent years in the field of electro-rheology is in designing and tailor-making these materials. There has also been a reasonable amount of experimental work on electro-rheological materials. However, little if any effort has been directed towards providing a comprehensive theory to describe the behavior of these materials. Recently, Rajagopal and Wineman [2] developed a mathematical model for field dependent materials based on the basic principles of continuum mechanics, which predicts behavior in keeping with experimentally observed phenomena. The theory of Rajagopal and Wineman [2] assumes that the electro-rheological suspension can be regarded as a single continuum. A good case can be made for such an approach on the basis of homogenization which yields average properties for the suspensions. However, it would be remiss not to try to model such a suspension via the theory of interacting continua (cf. Truesdell $[3,4]$ ). In such an approach, balance laws are postulated for each constituent which allows for interaction between the constituents including the possibility of generation of the individual species, chemical reactions, electro-mechanical, electro-chemical and other effects. The theory also allows us to account for the fact that we have particles moving through the fluid by including interactions such as drag, virtual mass effect, magnus effect, spin-lift, density gradient effects, buoyancy effects amongst others.

Mixtures of fluids and solid particulate media within the context of a purely mechanical theory of interacting continua have been studied by Massoudi [5], and Johnson et al. [6, 7]. These studies were primarily aimed at problems of fluidization and the transport of mixtures of fluids and granular solids. The mixture was assumed to be made up of a classical linearly viscous fluid and a granular solid. Thus, the partial stresses associated with the fluid and the granular material depend on the stretching tensors associated with both the fluid and solid motion in addition to the way in which the solid is distributed, which is described by a volume distribution function $v$ and the gradient of the volume distribution function. 
Here, we shall assume that the partial stresses associated with the fluid and the granular solid also depend on the electrical field $\mathbf{E}$. As a consequence of this, we find that there are contributions to the normal stress differences due to the electrical field $\mathbf{E}$, the gradient of the volume fraction, grad $v$ and also the squares of the stretching tensors $\mathbf{D}_{\mathrm{s}}^{2}$ and $\mathbf{D}_{\mathrm{f}}^{2}$, for the solid and fluid respectively.

An interesting consequence of our study is that an appropriately defined mixture viscosity changes with position, due to changes in the velocity gradients of the fluid and granular solid, though the individual viscosities of the fluid and granular solid are constant. We find that our mixture shear thickens.

The outline of the paper is as follows. In Section 2 we introduce the basic equations of mixture theory. In Section 3 we introduce the constitutive equations for electro-rheological materials. In the final section we discuss the flow of electro-rheological materials between parallel plates, namely plane Couette and Poiseuille flow.

\section{PRELIMINARIES AND BASIC EQUATIONS OF MIXTURE THEORY}

For the sake of completeness and continuity we shall provide a very concise review of the basic equations of mixture theory. A detailed and up-to-date account of the same can be found in the several appendices in [4].

The basic assumption of mixture theory is that each point in the domain of the mixture is occupied by a particle belonging to each constituent. That is, we assume that there is a "homogenized" equivalent continuum corresponding to each constituent, and these "homogenized" continua coexist. Let $\mathbf{X}^{\mathbf{s}}$ and $\mathbf{X}^{\mathbf{f}}$ denote the position of a solid particle and fluid particle, respectively, in their reference states. The motion of the solid (granular) continuum and the fluid are then given by invertible one-to-one maps

$$
\mathbf{x}^{\mathrm{s}}=\boldsymbol{\chi}^{\mathrm{s}}\left(\mathbf{X}^{\mathrm{s}}, t\right), \quad \mathbf{x}^{\mathrm{f}}=\boldsymbol{\chi}^{\mathrm{f}}\left(\mathbf{X}^{\mathrm{f}}, t\right) .
$$

The various kinematical terms associated with the two constituents can then be defined as

velocity

$$
\mathbf{u}^{\mathrm{s}}=\frac{\mathrm{d} \boldsymbol{x}^{\mathrm{s}}}{\mathrm{d} t}, \quad \mathbf{u}^{\mathrm{f}}=\frac{\mathrm{d} \boldsymbol{x}^{\mathrm{f}}}{\mathrm{d} t}
$$

acceleration

$$
\boldsymbol{\alpha}^{\mathrm{s}}=\frac{\mathrm{d}^{2} \boldsymbol{\chi}^{\mathrm{s}}}{\mathrm{d} t^{2}}, \quad \boldsymbol{\alpha}^{f}=\frac{\mathrm{d}^{2} \chi^{\mathrm{f}}}{\mathrm{d} t^{2}}
$$

velocity gradient

$$
\mathbf{L}^{\mathrm{s}}=\operatorname{grad} \mathbf{u}^{\mathrm{s}}, \quad \mathbf{L}^{\mathrm{f}}=\operatorname{grad} \mathbf{u}^{\mathrm{f}}
$$

stretching

$$
\mathbf{D}^{\mathrm{s}}=\frac{1}{2}\left(\mathbf{L}^{\mathrm{s}}+\left(\mathbf{L}^{\mathrm{s}}\right)^{T}\right), \quad \mathbf{D}^{\mathrm{f}}=\frac{1}{2}\left(\mathbf{L}^{\mathrm{f}}+\left(\mathbf{L}^{\mathrm{f}}\right)^{T}\right)
$$

spin

$$
\mathbf{W}^{\mathrm{s}}=\frac{1}{2}\left(\mathbf{L}^{\mathrm{s}}-\left(\mathbf{L}^{\mathrm{s}}\right)^{T}\right), \quad \mathbf{W}^{\mathrm{f}}=\frac{1}{2}\left(\mathbf{L}^{\mathrm{f}}-\left(\mathbf{L}^{\mathrm{f}}\right)^{T}\right) .
$$

Let $\rho^{s}$ and $\rho^{\mathrm{f}}$ denote the densities of the two constituents in the mixed state. The conservation of mass for the constituents takes the form

$$
\begin{aligned}
& \frac{\partial \rho^{\mathrm{s}}}{\partial t}+\operatorname{div}\left(\rho^{\mathrm{s}} \mathbf{u}^{\mathrm{s}}\right)=0 \\
& \frac{\partial \rho^{\mathrm{f}}}{\partial t}+\operatorname{div}\left(\rho^{\mathrm{f}} \mathbf{u}^{\mathrm{f}}\right)=0
\end{aligned}
$$

We assume there exists a partial stress tensor associated with each constituent. Then the 
balance of linear momentum for the two constituents takes the form

$$
\begin{aligned}
& \operatorname{div} \mathbf{T}^{\mathrm{s}}+\mathbf{b}+\rho^{\mathrm{s}} \mathbf{b}_{\mathrm{c}}=\rho^{\mathrm{s}} \frac{\mathrm{d}^{2} \chi^{\mathrm{s}}}{\mathrm{d} t^{2}}, \\
& \operatorname{div} \mathbf{T}^{\mathrm{f}}-\mathbf{b}+\rho^{\mathrm{f}} \mathbf{b}_{\mathrm{c}}=\rho^{\mathrm{f}} \frac{\mathrm{d}^{2} \chi^{\mathrm{f}}}{\mathrm{d} t^{2}},
\end{aligned}
$$

where b denotes the diffusive body forces on one constituent due to the presence of the other, and $\mathbf{b}_{\mathrm{c}}$ denotes the external body force field.

The balance of angular momentum takes the form that

$$
\mathbf{T}=\mathbf{T}^{\mathrm{s}}+\mathbf{T}^{\mathbf{f}}=\left(\mathbf{T}^{\mathrm{s}}+\mathbf{T}^{\mathbf{f}}\right)^{T}=\mathbf{T}^{T}
$$

Thus, while the total stress is symmetric, the individual partial stresses need not be so.

We shall not document the energy equation or the entropy inequality as it is not relevant to our subsequent discussion.

\section{CONSTITUTIVE EQUATIONS FOR ELECTRO-RHEOLOGICAL MATERIALS}

We shall assume that the partial stresses for the fluid $\mathbf{T}^{f}$, and the granular solid $\mathbf{T}^{\mathrm{s}}$, and the interactive body force $b$ have the following representation

$$
\begin{aligned}
& \mathbf{T}^{\mathrm{f}}=\mathbf{T}^{\mathrm{f}}\left(v, \operatorname{grad} v, \mathbf{E}, \mathbf{D}^{\mathrm{f}}, \mathbf{D}^{\mathrm{s}}\right), \\
& \mathbf{T}^{\mathrm{s}}=\mathbf{T}^{\mathrm{s}}\left(v, \operatorname{grad} v, \mathbf{E}, \mathbf{D}^{\mathrm{f}}, \mathbf{D}^{\mathrm{s}}\right),
\end{aligned}
$$

and

$$
\mathbf{b}=\mathbf{b}\left(\rho^{\mathrm{s}}, \rho^{\mathrm{f}}, \mathbf{u}^{\mathrm{s}}-\mathbf{u}^{\mathrm{f}}, \mathbf{a}^{\mathrm{sf}}, \mathbf{D}^{\mathrm{s}}, \mathbf{D}^{\mathbf{f}}, \mathbf{W}^{\mathrm{s}}-\mathbf{W}^{\mathbf{f}}\right),
$$

where

$$
\mathbf{a}^{\mathrm{sf}}=\left[\frac{\partial \mathbf{u}^{\mathrm{s}}}{\partial t}+\left[\operatorname{grad} \mathbf{u}^{\mathrm{s}}\right]\left(\mathbf{u}^{\mathrm{s}}-\mathbf{u}^{\mathrm{f}}\right)\right]-\left[\frac{\partial \mathbf{u}^{\mathrm{f}}}{\partial t}+\left[\operatorname{grad} \mathbf{u}^{\mathrm{f}}\right]\left(\mathbf{u}^{\mathbf{f}}-\mathbf{u}^{\mathrm{s}}\right)\right],
$$

and $v$ denotes the volume fraction of the solid.

The term $\mathbf{u}^{\mathrm{s}}-\mathbf{u}^{\mathrm{f}}$ in the expression for the diffusive body force $b$ incorporates the drag effect, while $\mathbf{a}^{\text {sf }}$ accounts for what is commonly referred to as the virtual mass effect which exists in virtue of the relative acceleration between the solid and fluid particles. The specific form for $\mathbf{a}^{\text {st }}$ that has been chosen is frame indifferent. The interactive body force $\mathbf{b}$ can also depend on the relative spin $\mathbf{W}^{\mathrm{s}}-\mathbf{W}^{\mathrm{f}}$, which is frame indifferent though the individual spins $\mathbf{W}^{\mathrm{s}}$ and $\mathbf{W}^{\mathrm{f}}$ are not so. In general the interaction term $\mathbf{b}$ can depend on the electric field $\mathbf{E}$. Also, frame indifferences requires that the constitutive functions are isotropic functions of all the variables involved. It is worthwhile pointing out that even though the fluid is non-conducting, we have assumed that the partial stress on the fluid depends on the electric field. The reason for this is that the partial stress in the granular solid is affected by the electric field and since the fluid and solid are jointly occupying the domain of the mixture, the stresses in the fluid are affected by the presence of the granular solid. If $\mathbf{t}_{\mathrm{s}}$ represents forces on solid particles due to the fluid, an electric field creates additional forces between particles. The basis for such a force is yet under investigation and forms the backbone of important research in material science.

To make the problem tractable, we shall make the simplifying assumption that

$$
\begin{aligned}
\mathbf{T}^{\mathrm{f}} & =\mathbf{T}^{\mathrm{f}}\left(v, \operatorname{grad} v, \mathbf{E}, \mathbf{D}^{\mathrm{f}}\right), \\
\mathbf{T}^{\mathrm{s}} & =\mathbf{T}^{\mathrm{s}}\left(v, \operatorname{grad} v, \mathbf{E}, \mathbf{D}^{\mathrm{s}}\right),
\end{aligned}
$$

and

$$
\mathbf{b}=\mathbf{b}\left(\mathbf{u}^{\mathrm{s}}-\mathbf{u}^{\mathrm{f}}, \mathbf{a}^{\mathrm{sf}}\right) \text {. }
$$


That is, the partial stress in each constituent depend only on the kinematics associated with the constituents and only the drag and virtual mass effect are important with regard to interaction. The first assumption is usually referred to as the principle of phase separation and can be traced back to the work of Adkins [8].

Let

$$
\mathbf{U}=\operatorname{grad} v \text {. }
$$

Then frame-indifference (cf. Truesdell [9]) requires that

$$
\mathbf{Q} \mathbf{T}^{\mathrm{f}}\left(v, \mathbf{U}, \mathbf{E}, \mathbf{D}^{\mathrm{f}}\right) \mathbf{Q}^{T}=\mathbf{T}^{\mathrm{f}}\left(v, \mathbf{Q U}, \mathbf{Q E}, \mathbf{Q} \mathbf{D}^{\mathrm{f}} \mathbf{Q}^{T}\right),
$$

$$
\mathbf{Q T} \mathbf{T}^{\mathrm{s}}\left(v, \mathbf{U}, \mathbf{E}, \mathbf{D}^{\mathrm{s}}\right) \mathbf{Q}^{T}=\mathbf{T}^{\mathbf{s}}\left(v, \mathbf{Q U}, \mathbf{Q E}, \mathbf{Q D} \mathbf{Q}^{T}\right), \quad \mathbf{Q b}\left(\mathbf{u}^{\mathrm{s}}-\mathbf{u}^{\mathrm{f}}, \mathbf{a}^{\mathrm{sf}}\right)=\mathbf{b}\left(\mathbf{Q}\left[\mathbf{u}^{\mathrm{s}}-\mathbf{u}^{\mathrm{f}}\right], \mathbf{Q}^{\mathrm{sf}}\right),
$$

for all $\mathbf{Q}$ that are orthogonal.

It follows that $\mathbf{T}^{\mathrm{f}}$ and $\mathbf{T}^{\mathrm{s}}$ have the following representation (cf. Spencer [10])

$$
\begin{aligned}
& \mathbf{T}=\alpha_{1} \mathbf{1}+\alpha_{2} \mathbf{U} \otimes \mathbf{U}+\alpha_{3} \mathbf{E} \otimes \mathbf{E}+\alpha_{4}(\mathbf{U} \otimes \mathbf{E}+\mathbf{E} \otimes \mathbf{U}) \\
& +\alpha_{5} \mathbf{D}^{\mathbf{c}}+\alpha_{6}\left(\mathbf{D}^{\mathrm{c}}\right)^{2}+\alpha_{7}\left(\mathbf{D}^{\prime} \mathbf{U} \otimes \mathbf{U}+\mathbf{U} \otimes \mathbf{D}^{\mathbf{l}} \mathbf{U}\right) \\
& +\alpha_{8}\left(\left(\mathbf{D}^{f}\right)^{2} \mathbf{U} \otimes \mathbf{U}+\mathbf{U} \otimes\left(\mathbf{D}^{f}\right)^{2} \mathbf{U}\right)+\alpha_{9}\left(\mathbf{D}^{\mathbf{f}} \mathbf{E} \otimes \mathbf{E}+\mathbf{E} \otimes \mathbf{D}^{\mathrm{f}} \mathbf{E}\right) \\
& +\alpha_{10}\left(\left(D^{f}\right)^{2} \boldsymbol{E} \otimes \boldsymbol{E}+\boldsymbol{E} \otimes\left(\boldsymbol{D}^{f}\right)^{2} \boldsymbol{E}\right)+\alpha_{11}\left(\mathbf{D}^{f} \mathbf{U} \otimes \mathbf{E}+\mathbf{E} \otimes \mathbf{D}^{f} \mathbf{U}\right) \\
& +\alpha_{12}\left(\mathbf{D}^{\mathrm{f}} \mathbf{E} \otimes \mathbf{U}+\mathbf{U} \otimes \mathbf{D}^{\mathrm{f}} \mathbf{E}\right)+\alpha_{13}\left(\left(\mathbf{D}^{f}\right)^{2} \mathbf{U} \otimes \mathbf{E}+\mathbf{E} \otimes\left(\mathbf{D}^{f}\right)^{2} \mathbf{U}\right) \\
& +\alpha_{14}\left(\left(\mathbf{D}^{\mathrm{f}}\right)^{2} \mathbf{E} \otimes \mathbf{U}+\mathbf{U} \otimes\left(\mathbf{D}^{\mathrm{f}}\right)^{2} \mathbf{E}\right)+\alpha_{15}\left[\left(\left(\mathbf{D}^{\mathrm{f}}\right)^{2} \mathbf{U} \otimes \mathbf{D}^{\mathrm{f}} \mathbf{E}+\mathbf{D}^{\mathrm{f}} \mathbf{E} \otimes\left(\mathbf{D}^{\mathrm{f}}\right)^{2} \mathbf{U}\right)\right. \\
& \left.-\left(\mathbf{D}^{\mathrm{f}}\right)^{2} \mathbf{E} \otimes \mathbf{D}^{\mathrm{f}} \mathbf{U}-\mathbf{D}^{\mathrm{f}} \mathbf{U} \otimes\left(\mathbf{D}^{\mathrm{f}}\right)^{2} \mathbf{E}\right] \text {, }
\end{aligned}
$$

and

$$
\begin{aligned}
& \mathbf{T}^{\mathrm{s}}=\beta_{1} \mathbf{1}+\beta_{2} \mathbf{U} \otimes \mathbf{U}+\beta_{3} \mathbf{E} \otimes \mathbf{E}+\beta_{4}(\mathbf{U} \otimes \mathbf{E}+\mathbf{E} \otimes \mathbf{U})+\beta_{5} \boldsymbol{D}^{*} \\
& +\beta_{6}\left(D^{s}\right)^{2}+\beta_{7}\left(D^{s} \mathbf{U} \otimes \mathbf{U}+\mathbf{U} \otimes \mathbf{D}^{s} \mathbf{U}\right)+\beta_{8}\left(\left(D^{s}\right)^{2} U \otimes U+U \otimes\left(D^{s}\right)^{2} U\right) \\
& +\beta_{9}\left(\mathbf{D}^{\mathrm{s}} \mathbf{E} \otimes \mathbf{E}+\mathbf{E} \otimes \mathbf{D}^{\mathrm{s}} \mathbf{E}\right)+\beta_{10}\left(\left(\mathbf{D}^{\mathrm{s}}\right)^{2} \mathbf{E} \otimes \mathbf{E}+\mathbf{E} \otimes\left(\mathbf{D}^{\mathrm{s}}\right)^{2} \mathbf{E}\right) \\
& +\beta_{11}\left(\mathbf{D}^{\mathrm{s}} \mathbf{U} \otimes \mathbf{E}+\mathbf{E} \otimes \mathbf{D}^{\mathrm{s}} \mathbf{U}\right)+\beta_{12}\left(\mathbf{D}^{\mathrm{s}} \mathbf{E} \otimes \mathbf{U}+\mathbf{U} \otimes \mathbf{D}^{\mathrm{s}} \mathbf{E}\right) \\
& +\beta_{13}\left(\left(\mathbf{D}^{\mathrm{s}}\right)^{2} \mathbf{U} \otimes \mathbf{E}+\mathbf{E} \otimes\left(\mathbf{D}^{\mathrm{s}}\right)^{2} \mathbf{U}\right)+\beta_{14}\left(\left(\mathbf{D}^{\mathrm{s}}\right)^{2} \mathbf{E} \otimes \mathbf{U}+\mathbf{U} \otimes\left(\mathbf{D}^{\mathrm{s}}\right)^{2} \mathbf{E}\right) \\
& +\beta_{15}\left[\left(\left(\mathbf{D}^{\mathrm{s}}\right)^{2} \mathbf{U} \otimes \mathbf{D}^{\mathrm{s}} \mathbf{E}+\mathbf{D}^{\mathrm{s}} \mathbf{E} \otimes\left(\mathbf{D}^{\mathrm{s}}\right)^{2} \mathbf{U}\right)-\left(\mathbf{D}^{\mathrm{s}}\right)^{2} \mathbf{E} \otimes \mathbf{D}^{\mathrm{s}} \mathbf{U}-\mathbf{D}^{\mathrm{s}} \mathbf{U} \otimes\left(\mathbf{D}^{\mathrm{s}}\right)^{2} \mathbf{E}\right]
\end{aligned}
$$

where the material parameters $\alpha_{i}, i=1, \ldots, 15$ are functions of the invariants

$$
\begin{gathered}
\operatorname{tr}(\mathbf{U} \otimes \mathbf{U}), \operatorname{tr}(\mathbf{E} \otimes \mathbf{E}), \operatorname{tr} \mathbf{D}^{\mathrm{f}}, \operatorname{tr}\left(\mathbf{D}^{\mathrm{f}}\right)^{2}, \operatorname{tr}\left(\mathbf{D}^{\mathrm{f}}\right)^{3}, \operatorname{tr}(\mathbf{U} \otimes \mathbf{E}), \operatorname{tr}\left(\mathbf{D}^{\mathrm{f}} \mathbf{U} \otimes \mathbf{U}\right), \\
\operatorname{tr}\left(\mathbf{D}^{\mathrm{f}} \mathbf{E} \otimes \mathbf{E}\right), \operatorname{tr}\left[\left(\mathbf{D}^{\mathrm{f}}\right)^{2} \mathbf{U} \otimes \mathbf{U}\right], \\
\operatorname{tr}\left(\left(\mathbf{D}^{\mathrm{f}}\right)^{2} \mathbf{E} \otimes \mathbf{E}\right), \operatorname{tr}(\mathbf{D E} \otimes \mathbf{U}), \operatorname{tr}\left(\mathbf{D}^{\mathrm{f}}\right)^{2} \mathbf{E} \otimes \mathbf{U},
\end{gathered}
$$

and $v$, and the material parameters $\beta_{i}, i=1, \ldots, 15$ are functions of the invariants

$$
\begin{gathered}
\operatorname{tr}(\mathbf{U} \otimes \mathbf{U}), \operatorname{tr}(\mathbf{E} \otimes \mathbf{E}), \operatorname{tr} \mathbf{D}^{\mathrm{s}}, \operatorname{tr}\left(\mathbf{D}^{\mathrm{s}}\right)^{2}, \operatorname{tr}\left(\mathbf{D}^{s}\right)^{3}, \operatorname{tr}(\mathbf{U} \otimes \mathbf{E}), \operatorname{tr}\left(\mathbf{D}^{\mathrm{s}} \mathbf{U} \otimes \mathbf{U}\right), \\
\operatorname{tr}\left(\mathbf{D}^{\mathrm{s}} \mathbf{E} \otimes \mathbf{E}\right), \operatorname{tr}\left[\left(\mathbf{D}^{\mathrm{s}}\right)^{2} \mathbf{U} \otimes \mathbf{U}\right], \\
\operatorname{tr}\left[\left(\mathbf{D}^{\mathrm{s}}\right)^{2} \mathbf{E} \otimes \mathbf{E}\right], \operatorname{tr}\left(\mathbf{D}^{\mathrm{s}} \mathbf{E} \otimes \mathbf{U}\right), \operatorname{tr}\left[\left(\mathbf{D}^{\mathrm{s}}\right)^{2} \mathbf{E} \otimes \mathbf{U}\right],
\end{gathered}
$$

and $v$.

The constitutive expressions (18) and (19) have to be substituted respectively into (5) and (6) to obtain the equations of motion for the fluid and solid constituents. It is, of course, essential to assume a specific constitutive expression for the interaction force $b$ which incorporates the effects of drag, virtual mass, buoyancy, lift and other forces which appear due to the presence of a second constituent (cf. Johnson et al. [11]). A good starting point is the inclusion of the effects due to drag and virtual mass, i.e.

$$
\mathbf{b}=\gamma_{1}\left(\mathbf{u}^{\mathbf{s}}-\mathbf{u}^{\mathbf{f}}\right)+\gamma_{2} \mathbf{a}^{\mathbf{s i}},
$$

where $\gamma_{1}$ and $\gamma_{2}$ are in general functions of $v$. 
It is possible that the constitutive relations (12) and (13) are simpler than those envisaged. For example, it might be likely that the stress in the fluid is insensitive to the gradients in the volume fraction of the granular solid. It is also, at this juncture, unclear how the electric field affects the stress in the fluid and solid. It is possible that the electric field may not have significant effects on both the stresses. On the other hand, it might, and we would also have to include it in the constitutive expression for the interactive force $\mathbf{b}$.

We note that the total stress (or the mixture stress) is defined through $\mathbf{T}=\mathbf{T}^{\mathrm{s}}+\mathbf{T}^{\mathrm{f}}$. Then we necd the cocfficients $\alpha^{\mathrm{s}}, \beta^{\mathrm{s}}$ and $\gamma^{\mathrm{s}}$ to tend to the correct limits as $v \rightarrow 0$, namely $\mathbf{T}^{\mathrm{f}}$. It is customary in the two phase flow literature to express the mixture stress $\mathbf{T}=(1-v) \hat{\mathbf{T}}^{\mathbf{f}}+\hat{\mathbf{T}}^{\mathbf{s}}$. Of course, our $\mathbf{T}^{\mathrm{s}}$ and $\mathbf{T}^{\mathrm{f}}$ are related to $\hat{\mathbf{T}}^{\mathrm{s}}$ and $\hat{\mathbf{T}}^{\mathrm{f}}$, appropriately. We shall choose to work with the expressions $\mathbf{T}^{\mathrm{f}}$ and $\mathbf{T}^{\mathrm{s}}$ given in (18) and (19), respectively. Also, we are not interested in the limit $v \rightarrow 1$ (or $v \rightarrow v_{\mathrm{m}}, v_{\mathrm{m}}$ being the maximum packing). We are in fact interested when sufficient amount of both the carrier fluid and the particulate media are present in the mixture.

We notice that in order for the theory to be of practical utility, we need to simplify the constitutive equations drastically. Otherwise, we are faced with a theory that incorporates, in general, 32 material functions $\alpha_{1}, \ldots, \alpha_{15}, \beta_{1}, \ldots, \beta_{15}, \gamma_{1}$ and $\gamma_{2}$, and even if these material moduli, which are functions of the various invariants defined in (20) and (21) and possibly $v$, are constants there are way too many of them to be determined in any reasonable experimental program. This will become evident from the next section where we shall study what is probably the simplest flow problems, namely plane Couette and Poiseuille flow between parallel plates. In the final sections we shall discuss some simplifications to the model (18), (19) and (22).

\section{EXAMPLE: FLOW BETWEEN PARALLEL PLANE}

Let us consider the problem of unidirectional steady flow of a mixture modeled by (18), (19) and (22) between infinite parallel plates (cf. Fig. 1). Suppose that the velocity fields associated with the fluid and solid, the volume fraction, and the electrical field have the form

$$
\mathbf{u}^{\mathrm{f}}=\mathbf{u}_{\mathrm{f}}(y) \mathbf{i}, \quad \mathbf{u}^{\mathrm{s}}=\mathbf{u}_{\mathrm{s}}(y) \mathbf{i}, \quad v=v(y), \quad \mathbf{E}=E \mathbf{j} .
$$

It follows from (11), (18), (19), and (22) that

$$
\begin{aligned}
\mathbf{T}^{\mathrm{f}}= & (\mathbf{i} \otimes \mathbf{i})\left\{\alpha_{1}+\left(u_{\mathrm{f}}^{\prime}\right)^{2} \frac{\alpha_{6}}{4}\right\}+[(\mathbf{i} \otimes \mathbf{j})+(\mathbf{j} \otimes \mathbf{i})]\left\{u_{\mathrm{f}}^{\prime} \frac{\alpha_{5}}{2}+u_{\mathrm{f}}^{\prime}\left(v^{\prime}\right)^{2} \frac{\alpha_{7}}{2}+\left(u_{\mathrm{f}}^{\prime}\right) E^{2} \frac{\alpha_{9}}{2}\right. \\
& \left.+u_{\mathrm{f}}^{\prime} v^{\prime} E \frac{\left(\alpha_{11}+\alpha_{12}\right)}{2}\right\}+(\mathbf{j} \otimes \mathbf{j})\left\{\alpha_{1}+\left(v^{\prime}\right)^{2} \alpha_{2}+E^{2} \alpha_{3}+2 E v^{\prime} \alpha_{4}+\frac{\left(u_{\mathrm{f}}^{\prime}\right)^{2} \alpha_{6}}{4}\right. \\
& \left.+\frac{1}{4}\left(u_{\mathrm{f}}^{\prime}\right)^{2}\left(v^{\prime}\right)^{2} \alpha_{8}+\left(u_{\mathrm{f}}^{\prime}\right)^{2} E^{2} \frac{\alpha_{10}}{4}+\left(u_{\mathrm{f}}^{\prime}\right)^{2} v^{\prime} E \frac{\left(\alpha_{13}+\alpha_{14}\right)}{4}\right\}+(\mathbf{k} \otimes \mathbf{k}) \alpha_{1}, \\
\mathbf{T}^{\mathrm{s}}= & (\mathbf{i} \otimes \mathbf{i})\left\{\beta_{1}+\left(u_{\mathrm{s}}^{\prime}\right)^{2} \frac{\beta_{6}}{4}\right\}+[(\mathbf{i} \otimes \mathbf{j})+(\mathbf{j} \otimes \mathbf{i})]\left\{u_{\mathrm{s}}^{\prime} \frac{\beta_{5}}{2}+u_{\mathrm{s}}^{\prime}\left(v^{\prime}\right)^{2} \frac{\beta_{7}}{2}+\left(u_{\mathrm{s}}^{\prime}\right) E^{2} \frac{\beta_{9}}{2}\right. \\
& \left.+u_{\mathrm{s}}^{\prime} v^{\prime} E \frac{\left(\beta_{11}+\beta_{12}\right)}{2}\right\}+(\mathbf{j} \otimes \mathbf{j})\left\{\beta_{1}+\left(v^{\prime}\right)^{2} \beta_{2}+E^{2} \beta_{3}+2 E v^{\prime} \beta_{4}+\frac{\left(u_{\mathrm{f}}^{\prime}\right)^{2} \beta_{6}}{4}\right. \\
& \left.+\left(u_{\mathrm{s}}^{\prime}\right)^{2}\left(v^{\prime}\right)^{2} \frac{\beta_{8}}{4}+\left(u_{\mathrm{s}}^{\prime}\right)^{2} E^{2} \frac{\beta_{10}}{4}+\left(u_{\mathrm{s}}^{\prime}\right)^{2} v^{\prime} E \frac{\left(\beta_{13}+\beta_{14}\right)}{4}\right\}+(\mathbf{k} \otimes \mathbf{k}) \beta_{1}, \\
& \mathbf{b}=\gamma_{1}\left(u_{\mathrm{s}}-u_{\mathrm{f}}\right) \mathbf{i} .
\end{aligned}
$$

The constitutive expressions for the partial Cauchy stresses $\mathbf{T}^{\mathrm{f}}$ and $\mathbf{T}^{\mathrm{s}}$ reduce to the model of Johnson et al. [5] for a mixture of a solid infused with particles, when the electrical field $\mathbf{E} \equiv \mathbf{0}$. Even in this simplified case, and when the material coefficients are constants the balance of 
(a)

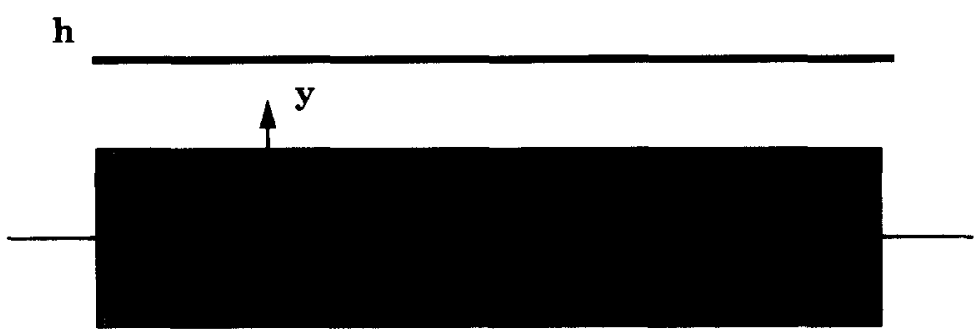

$-\mathbf{h}$

(b)

h

$\mathbf{U}$

$\mathbf{0}$

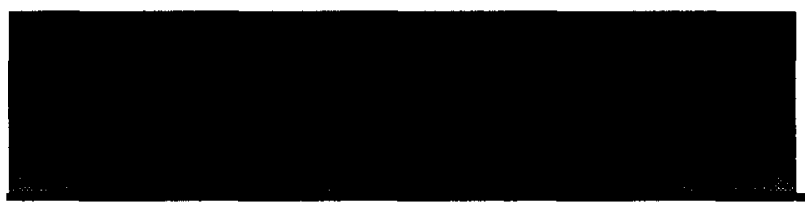

Fig. 1. (a) Coordinate system with top plate stationary. Shaded region is the plug region of constant velocity; (b) conrdinate system with top plate moving. Shaded region is the plug region of rest.

linear momenta are a system of coupled highly non-linear ordinary differential equations which have to be solved numerically (cf. Johnson et al. [5]). Here, we are more interested in recognizing some simple features associated with the flow due to the presence of the electric field.

The total stress $\mathbf{T}$ [cf. (7)] is given by

$$
\begin{aligned}
\mathbf{T}= & (\mathbf{i} \otimes \mathbf{i})\left\{\left(\alpha_{1}+\beta_{1}\right)+\frac{1}{4}\left(u_{\mathrm{f}}^{\prime}\right)^{2}+\alpha_{6}+\left(u_{\mathrm{s}}^{\prime}\right)^{2} \frac{1}{4} \beta_{6}\right\}+[(\mathbf{i} \otimes \mathbf{j})+(\mathbf{j} \otimes \mathbf{i})]\left\{u_{\mathrm{f}}^{\prime} \frac{\alpha_{5}}{2}+u_{\mathrm{s}}^{\prime} \frac{\beta_{5}}{2}\right. \\
& \left.+\frac{1}{2} v^{\prime 2}\left(u_{\mathrm{f}}^{\prime} \alpha_{7}+u_{\mathrm{s}}^{\prime} \beta_{7}\right)+\frac{1}{2} E^{2}\left[\left(u_{\mathrm{f}}^{\prime}\right) \alpha_{9}+\left(u_{\mathrm{s}}^{\prime}\right) \beta_{\mathrm{q}}\right]+\frac{1}{2} E v^{\prime}\left[u_{\mathrm{f}}^{\prime}\left(\alpha_{11}+\alpha_{12}\right)+u_{\mathrm{s}}^{\prime}\left(\beta_{11}+\beta_{12}\right)\right]\right\} \\
& +(j \otimes j)\left\{\left(\alpha_{1}+\beta_{1}\right)+v^{\prime 2}\left(\alpha_{2}+\beta_{2}\right)+E^{2}\left(\alpha_{3}+\beta_{3}\right)+2 E v^{\prime}\left(\alpha_{4}+\beta_{4}\right)+\frac{1}{4}\left(u_{\mathrm{f}}^{\prime}\right)^{2} \alpha_{6}\right. \\
& +\frac{1}{4}\left(u_{\mathrm{s}}^{\prime}\right)^{2} \beta_{6}+\frac{1}{4} v^{\prime 2}\left[\left(u_{\mathrm{f}}^{\prime}\right)^{2} \alpha_{8}+\left(u_{\mathrm{s}}^{\prime}\right)^{2} \beta_{8}\right]+\frac{1}{4} E^{2}\left[\left(u_{\mathrm{f}}^{\prime}\right)^{2} \alpha_{10}+\left(u_{\mathrm{s}}^{\prime}\right)^{2} \beta_{10}\right] \\
& \left.+\frac{1}{4} E v^{\prime}\left[\left(u_{\mathrm{f}}^{\prime}\right)^{2}\left(\alpha_{13}+\alpha_{14}\right)+\left(u_{\mathrm{s}}^{\prime}\right)^{2}\left(\beta_{13}+\beta_{14}\right)\right]\right\}+(\mathbf{k} \otimes \mathbf{k})\left\{\alpha_{1}+\beta_{1}\right\} .
\end{aligned}
$$

Next, wc compute the normal stress differences

$$
\begin{aligned}
& T_{11}-T_{22}=-\left\{\left(v^{\prime}\right)^{2}\left(\alpha_{2}+\beta_{2}\right)+E^{2}\left(\alpha_{3}+\beta_{3}\right)+2 E v^{\prime}\left(\alpha_{4}+\beta_{4}\right)+\frac{1}{4}\left(v^{\prime}\right)^{2}\left[\left(u_{\mathrm{f}}^{\prime}\right)^{2} \alpha_{8}+\left(u_{\mathrm{s}}^{\prime}\right)^{2} \beta_{8}\right]\right. \\
&\left.+\frac{1}{4} E^{2}\left[u_{\mathrm{f}}^{\prime} \alpha_{10}+u_{\mathrm{s}}^{\prime} \beta_{10}\right]+\frac{1}{4} E v^{\prime}\left[\left(u_{\mathrm{f}}^{\prime}\right)^{2}\left(\alpha_{13}+\alpha_{14}\right)+\left(u_{\mathrm{s}}^{\prime}\right)^{2}\left(\beta_{13}+\beta_{14}\right)\right]\right\} \\
& T_{11}-T_{33}-\frac{1}{4}\left[\left(u_{\mathrm{f}}^{\prime}\right)^{2} \alpha_{\mathrm{f}}+\left(u_{\mathrm{s}}^{\prime}\right)^{2} \beta_{6}\right],
\end{aligned}
$$


and thus both normal stress differences are in general non-zero. The electrical field, however, does not contribute to the normals stress difference $T_{11}-T_{33}$ if the material functions $\alpha_{6}$ and $\beta_{6}$ are constants. However, in general the material coefficients will depend on the electrical field and thus the normal stress difference $T_{11}-T_{33}$ will depend on the applied electric field. We also observe that the electrical field induces normal stress differences even when the particles are homogeneously dispersed, i.e. $v=$ constant.

It is interesting to observe that even in the absence of flow, inhomogeneous distribution of the particles (i.e. $v \neq 0$ ) gives rise to normal stress difference $T_{11}-T_{22}$.

Next, the total shear stress $T_{12}$ is given by

$$
\begin{aligned}
T_{12}= & \left\{\frac{1}{2} \alpha_{5}+\frac{1}{2}\left(v^{\prime}\right)^{2} \alpha_{7}+\frac{1}{2} E^{2} \alpha_{9}+\frac{1}{2} E v^{\prime}\left(\alpha_{11}+\alpha_{12}\right)\right\} u_{\mathrm{f}}^{\prime} \\
& +\left\{\frac{1}{2} \beta_{5}+\frac{1}{2}\left(v^{\prime}\right)^{2} \beta_{7}+\frac{1}{2} E^{2} \beta_{9}+\frac{1}{2} E v^{\prime}\left(\beta_{11}+\beta_{12}\right)\right\} u_{\mathrm{s}}^{\prime} \\
= & {\left[\mu_{\mathrm{f}}\left(v, v^{\prime}, E, u_{\mathrm{f}}^{\prime}\right)\right] u_{\mathrm{f}}^{\prime}+\left[\mu_{\mathrm{s}}\left(v, v^{\prime}, E, u_{\mathrm{f}}^{\prime}\right)\right] u_{\mathrm{s}}^{\prime}, }
\end{aligned}
$$

where $\mu_{\mathrm{f}}$ and $\mu_{\mathrm{s}}$ represent generalized shear viscosity functions that depend on the electric field and the manner in which the particles are distributed in addition to the shear rates.

We notice that even when the material is homogeneously dispersed, i.e. $v=$ constant, the electric field can cause changes in the generalized viscosities $\mu_{\mathrm{f}}$ and $\mu_{\mathrm{s}}$. Also, in the absence of an electric field, the distribution of the solid particles can change the generalized viscosity.

When the particles are homogeneously dispersed the viscosities $\mu_{\mathrm{f}}$ and $\mu_{\mathrm{s}}$ have the form

$$
\begin{aligned}
& \mu_{\mathrm{r}}\left(v, v, E, u_{\mathrm{f}}^{\prime}\right)=\frac{1}{2}\left\{\alpha_{5}+E^{2} \alpha_{9}\right\}, \\
& \mu_{\mathrm{s}}\left(v, v^{\prime}, E, u_{\mathrm{s}}^{\prime}\right)=\frac{1}{2}\left\{\beta_{5}+E^{2} \beta_{9}\right\},
\end{aligned}
$$

where

$$
\begin{aligned}
& \alpha_{5,9}=\alpha_{5,9}\left(E^{2},\left(u_{\mathrm{f}}^{\prime}\right)\right), \\
& \beta_{5,9}=\beta_{5,9}\left(E^{2},\left(u_{s}^{\prime}\right)\right) .
\end{aligned}
$$

Thus, even the simplest case when the material moduli are constant, the electrical field can cause the material to shear thicken. Moreover, the electrical field enters the expressions for the generalized viscosities in a non-linear fashion and thus can produce a significant change in the viscosity for large values of the field.

Henceforth, we shall assume that the carrier fluid is incompressible. Thus, the function $\alpha_{1}$ should be replaced by the indeterminate field $-p$. In this case the material can undergo only isochoric motions and hence has to meet

$$
\operatorname{div} u_{\mathrm{f}}=\mathbf{0} \text {. }
$$

In the case of $(23)_{1}$, this condition is met automatically.

We now turn our attention to deriving the balance of linear momentum of each constituent. It follows from (5), (6), (24) and (25) that

$$
\begin{gathered}
\frac{1}{2}\left\{u_{\mathrm{f}}^{\prime} \alpha_{5}+\left(v^{\prime}\right)^{2}\left[u_{\mathrm{f}}^{\prime} \alpha_{7}\right]+E^{2}\left(u_{\mathrm{f}}^{\prime}\right) \alpha_{9}+E v^{\prime}\left[u_{\mathrm{f}}^{\prime}\left(\alpha_{11}+\alpha_{12}\right)\right]\right\}^{\prime}-\gamma_{1}\left(u_{\mathrm{f}}-u_{\mathrm{s}}\right)=\frac{\partial p}{\partial x}=K_{1}=\text { const } \\
\left\{\left(v^{\prime}\right)^{2} \alpha_{2}+E^{2} \alpha_{3}+2 E v^{\prime} \alpha_{4}+\frac{\left(u_{\mathrm{f}}^{\prime}\right)^{2} \alpha_{6}}{4}+\frac{1}{2}\left(u_{\mathrm{f}}^{\prime}\right)^{2}\left(v^{\prime}\right)^{2} \alpha_{8}+\frac{\left(u_{\mathrm{f}}^{\prime}\right)^{2} E^{2} \alpha_{10}}{4}\right. \\
\left.+\left(u_{\mathrm{f}}^{\prime}\right)^{2} v^{\prime} E \frac{\left(\alpha_{13}+\alpha_{14}\right)}{4}\right\}^{\prime}=\frac{\partial p}{\partial y}, \\
\frac{1}{2}\left\{u_{\mathrm{s}}^{\prime} \beta_{5}+\left(v^{\prime}\right)^{2}\left[u_{\mathrm{s}}^{\prime} \beta_{7}\right]+E^{2}\left(u_{\mathrm{s}}^{\prime}\right) \beta_{9}+E v^{\prime}\left[u_{\mathrm{f}}^{\prime}\left(\beta_{11}+\beta_{12}\right)\right]\right\}^{\prime}+\gamma_{1}\left(u_{\mathrm{f}}-u_{\mathrm{s}}\right)=0 \\
\left\{\beta_{1}+\left(v^{\prime}\right)^{2} \beta_{2}+E^{2} \beta_{3}+2 E v^{\prime} \beta_{4}+\frac{\left(u_{\mathrm{s}}^{\prime}\right)^{2} \beta_{\mathrm{f}}}{4}+\frac{1}{2}\left(u_{\mathrm{s}}^{\prime}\right)^{2}\left(v^{\prime}\right) \beta_{8}+\frac{\left(u_{\mathrm{f}}^{\prime}\right)^{2} E^{2} \beta_{10}}{4}+\frac{\left(u_{\mathrm{s}}^{\prime}\right)^{2} v^{\prime} E\left(\beta_{13}+\beta_{14}\right)}{4}\right\}^{\prime}=0 .
\end{gathered}
$$


The assignment of boundary conditions is not usually straightforward in mixture theory. If traction boundary conditions are involved, then we are faced with the daunting task of prescribing individual partial tractions, when in most problems we are only aware of the total traction. A method for overcoming this difficulty within the context of some special mixtures has been provided by Rajagopal et al. [12]. $\dagger$ If we are studying problems involving velocity boundary conditions, we would have no difficulty if we assume both the constituents satisfy the adherence condition. However, it is not clear that the particulate material has to adhere to the boundary and even in this case we might have an indeterminacy in the problem. In fact, even in the case of a purely granular solid the nature of the boundary condition is a thorny issue and far from being settled. Here, we shall assume that both the constituents adhere to the boundary. Thus (cf. Fig. 1)

$$
\begin{array}{ll}
u_{\mathrm{s}}(0)=0, & u_{\mathrm{s}}(h)=0, \\
u_{\mathrm{f}}(0)=0, & u_{\mathrm{f}}(h)=0 .
\end{array}
$$

Thus, we need to solve (35) and (36) subject to (39) and (40). As we mentioned earlier this would have to be done numerically, and even in the absence of the electrical field this is a reasonably tedious calculation (cf. Johnson et al. $[5,6]$ ).

To make the theory have some practical utility it is necessary to make reasonable simplifications which retain the important physical effects, but within a structure with far fewer material parameters. With this in mind, we turn our attention towards a re-evaluation of the basic assumption on the forms of the constitutive equations $\mathbf{T}^{\mathrm{s}}$ and $\mathbf{T}^{\mathrm{f}}$. If we are interested in slow flows of electro-rheological materials in which the volume distribution of the particles is more or less uniform in the sense that gradients of $v$ are small, we can assume as a starting point that $\mathbf{T}^{\mathrm{s}}$ depends linearly on $\mathbf{D}^{\mathrm{s}}$ and $\mathbf{U}$. As we are interested in problems where $\mathbf{E}$ is large, we cannot ignore the quadratic terms in $\mathbf{E}$. Since the carrier fluid is Newtonian and non-conducting, and if we furthermore assume that the stress $\mathbf{T}^{\mathrm{f}}$ does not depend on $v$, the effect of the particulate distributions manifesting themselves through the interaction terms, the expressions for the partial solid stress $\mathbf{T}^{\mathrm{s}}$ and the fluid stress $\mathbf{T}^{\mathrm{f}}$ take the form:

$$
\begin{aligned}
\mathbf{T}^{\mathrm{s}}=\beta_{1} \mathbf{1} & +\beta_{2} \mathbf{U} \otimes \mathbf{U}+\beta_{3} \mathbf{E} \otimes \mathbf{E}+\beta_{4}(\mathbf{U} \otimes \mathbf{E}+\mathbf{E} \otimes \mathbf{U})+\beta_{5} \mathbf{D}^{\mathrm{s}}+\beta_{9}\left(\mathbf{D}^{\mathrm{s}} \mathbf{E} \otimes \mathbf{E}+\mathbf{E} \otimes \mathbf{D}^{\mathrm{s}} \mathbf{E}\right) \\
& +\beta_{11}\left(\mathbf{D}^{\mathrm{s}} \mathbf{U} \otimes \mathbf{E}+\mathbf{E} \otimes \mathbf{D}^{\mathrm{s}} \mathbf{U}\right)+\beta_{12}\left(\mathbf{D}^{\mathrm{s}} \mathbf{E} \otimes \mathbf{U}+\mathbf{U} \otimes \mathbf{D}^{\mathrm{s}} \mathbf{E}\right)
\end{aligned}
$$

and

$$
\mathbf{T}^{\mathrm{f}}=-p \mathbf{1}+\alpha_{3} \mathbf{E} \otimes \mathbf{E}+\alpha_{5} \mathbf{D}^{\mathrm{f}}+\alpha_{9}\left(\mathbf{D}^{\mathrm{f}} \mathbf{E} \otimes \mathbf{E}+\mathbf{E} \otimes \mathbf{D}^{\mathrm{f}} \mathbf{E}\right) .
$$

We now consider an example which illustrates the complexity involved in the simplest of boundary value problems.

The assumption of linearity in $\mathbf{D}^{\mathrm{s}}$ and $\mathbf{U}$ for instance allows the material coefficients to depend on the $\operatorname{tr} \mathbf{D}^{\mathrm{s}}$, and since there are no restrictions on the dependence of $\mathbf{E}$, they can also depend on the various invariants which depend on $\mathbf{E}$, and also non-linearly on $v$. We shall make the further assumption that all the material moduli are constants, except for $\beta_{1}$. The coefficient $\beta_{1}$ plays the role of pressure in a compressible material and thus depends on $v$. If we want an equation of state similar to an ideal gas we would pick $\beta_{1} \sim \kappa v$ (cf. Rajagopal and Massoudi [13]). There is also some information on the manner in which these material coefficients depend on $v$ for pure granular materials. However, we shall not get into a discussion of thesc issucs here as they are not central to our illustrations.

Since we shall be interested in slow flows, the relative acceleration effect $\mathbf{a}^{\text {sf }}$ can be ignored and the interactive force simplifies to

$$
\mathbf{b}=\gamma_{1}\left(\mathbf{u}^{\mathrm{s}}-\mathbf{u}^{\mathrm{f}}\right)=\gamma_{1} \mathbf{i}\left(u^{\mathrm{s}}-u^{\mathrm{f}}\right) \text {. }
$$

$\dagger$ For problems involving non-linearly elastic solids infused with fluids, at saturation, Rajagopal et al. [12] require that the variation in the Helmholtz free energy equal the work done by the external tractions. This thermodynamic criterion provides an additional condition which is used in place of a boundary condition. 
The study of Johnson et al. [6,7], as we mentioned earlier, considers the problem when $E=0$.

Here, we shall consider the other extreme case when $v^{\prime}=0$ (i.e. the material is homogeneously dispersed). In this case, we obtain

$$
\begin{gathered}
\frac{1}{2}\left\{\alpha_{5} u_{\mathrm{f}}^{\prime}+E^{2} \alpha_{9}\left(u_{\mathrm{f}}^{\prime}\right)\right\}^{\prime}-\gamma_{1}\left(u_{\mathrm{f}}-u_{\mathrm{s}}\right)=\frac{\partial p}{\partial x}=K_{1}, \\
\frac{\partial p}{\partial y}=0, \\
\frac{1}{2}\left\{\beta_{5} u_{\mathrm{s}}^{\prime}+E^{2} \beta_{9}\left(u_{\mathrm{s}}^{\prime}\right)\right\}^{\prime}+\gamma_{1}\left(u_{\mathrm{f}}-u_{\mathrm{s}}\right)=0 .
\end{gathered}
$$

When $E$ and $v$ are constant, (38) is automatically satisfied. We thus notice that the flow is due to the pressure gradient in the carrier fluid, the solid particles moving by virtue of the interaction forces due to the fluid on the solid particles.

On adding (44) and (45), it immediately follows that equations (44) and (46) can be expressed as

$$
\begin{gathered}
\left(\mu_{\mathrm{f}} u_{\mathrm{f}}^{\prime}\right)^{\prime}-\gamma_{\mathrm{t}}\left(u_{\mathrm{f}}-u_{\mathrm{s}}\right)=k_{1}, \\
\left(\mu_{\mathrm{s}} u_{\mathrm{s}}^{\prime}\right)^{\prime}+\gamma_{1}\left(u_{\mathrm{f}}-u_{\mathrm{s}}\right)=0 .
\end{gathered}
$$

From (48) we get

$$
u_{\mathrm{f}}=-\frac{\mu_{\mathrm{s}} u_{\mathrm{s}}^{\prime \prime}}{\gamma_{1}}+u_{\mathrm{s}}
$$

and

$$
u_{\mathrm{f}}^{\prime \prime}=-\frac{\mu_{\mathrm{s}} u_{\mathrm{s}}^{\mathrm{IV}}}{\gamma_{1}}+u_{\mathrm{s}}^{\prime \prime}
$$

Substituting (49) and (50) in equation (47) we obtain

$$
u_{\mathrm{s}}^{\prime V}-\frac{\gamma_{1}\left(\mu_{\mathrm{f}}+\mu_{\mathrm{s}}\right)}{\mu_{\mathrm{f}} \mu_{\mathrm{s}}} u_{\mathrm{s}}^{\prime \prime}+\frac{k_{1} \gamma}{\mu_{\mathrm{f}} \mu_{\mathrm{s}}}=0, \quad k_{1}<0,
$$

which implies that

$$
u_{\mathrm{s}}=\frac{c_{1}}{m_{1}^{2}} \mathrm{e}^{m_{1} y}+\frac{c_{2}}{m_{1}^{2}} \mathrm{e}^{-m_{1} y}+\frac{k_{1} y^{2}}{2\left(\mu_{\mathrm{f}}+\mu_{\mathrm{s}}\right)}+c_{4} y+c_{s} .
$$

Using (49) and (52) we obtain

$$
u_{\mathrm{f}}=-\frac{\mu_{\mathrm{s}}}{\gamma_{1}}\left\{c_{1} \mathrm{e}^{m_{1} y}+c_{2} \mathrm{e}^{-m_{1} y}+\frac{k_{1}}{\left(\mu_{\mathrm{f}}+\mu_{\mathrm{s}}\right)}\right\}+\frac{c_{1}}{m_{1}^{2}} \mathrm{e}^{m_{1} y}+\frac{c_{2}}{m_{1}^{2}} \mathrm{e}^{-m_{1} y}+\frac{k_{1} y^{2}}{2\left(\mu_{\mathrm{f}}+\mu_{\mathrm{s}}\right)}+c_{4} y+c_{5}
$$

where

$$
m_{\mathrm{l}}^{2}=\frac{\gamma_{1}\left(\mu_{\mathrm{f}}+\mu_{\mathrm{s}}\right)}{\mu_{\mathrm{f}} \mu_{\mathrm{s}}}
$$

The mixture velocity $u_{m}$ and mixture viscosity $\mu_{m}$ are defined through

$$
\begin{gathered}
u_{\mathrm{m}}=\frac{\rho^{\mathrm{s}} u_{\mathrm{s}}+\rho^{\mathrm{f}} u_{\mathrm{f}}}{\rho^{\mathrm{m}}} \\
\rho^{\mathrm{m}}=\rho^{\mathrm{s}}+\rho^{\mathrm{f}} \\
\mu_{\mathrm{m}}=\frac{\mu_{\mathrm{f}} u_{\mathrm{f}}^{\prime}+\mu_{\mathrm{s}} u_{\mathrm{s}}^{\prime}}{u_{\mathrm{m}}^{\prime}}
\end{gathered}
$$


where $\rho^{\mathrm{m}}, \rho^{\mathrm{s}}, \rho^{\mathrm{f}}$ are the densities of the mixture solid and fluid respectively. In defining the mixture viscosity, we have used the fact that the shear stress in the mixture is the sum of the partial shear stresses. Moreover, since we have assumed that the volume fractions are constant they do not appear in the expression for the mixture viscosity. However, if volume fractions are allowed to vary, then even the component viscosities $\mu_{1}$ and $\mu_{2}$ would depend on the local volume fraction of the constituent and are not necessarily constant.

When electro-rheological fluids are sheared, in the presence of an electrical field, they exhibit a Bingham fluid-like behavior in that they flow only after a yield stress $\left[\sigma_{0}(E)\right]$ is reached.

In order to determine the constants $c_{1}, c_{2}, c_{4}$ and $c_{5}$, we consider the steady flow of a mixture between two flat plates with the top plate being stationary [Fig. 1(a)] and the top plate moving (Fig. 1(b)], the bottom plate being always held fixed.

For the electro-rheological fluid to flow the shear stress should be greater than or equal to the yield stress of the mixture.

Thus, for flow to take place we need

$$
\mu_{\mathrm{m}} u_{\mathrm{m}}^{\prime} \geq \sigma_{0}
$$

and from equation (57) at $y^{*}$

$$
\left.\mu_{\mathrm{f}} u_{\mathrm{f}}^{\prime}\right|_{y^{*}}+\left.\mu_{\mathrm{s}} u_{\mathrm{s}}^{\prime}\right|_{y^{*}}=\sigma_{0}
$$

On substituting for $u_{\mathrm{f}}^{\prime}$ and $u_{\mathrm{s}}^{\prime}$ at $y^{*}$ we get

$\frac{-\mu_{\mathrm{s}} \mu_{\mathrm{f}} m_{1}}{\gamma_{1}}\left\{c_{1} \mathrm{e}^{m_{1} y^{*}}-c_{2} \mathrm{e}^{-m_{1} y^{*}}\right\}+\frac{c_{1}}{m_{1}}\left(\mu_{\mathrm{f}}+\mu_{\mathrm{s}}\right) \mathrm{e}^{m_{1} y^{*}}-\frac{c_{2}}{m_{1}}\left(\mu_{\mathrm{f}}+\mu_{\mathrm{s}}\right) \mathrm{e}^{-m_{1} y^{*}}+c_{4}\left(\mu_{\mathrm{f}}+\mu_{\mathrm{s}}\right)+k_{1} y^{*}=\sigma_{0}$.

Equation (59) is evaluated numerically to obtain the value of $y^{*}$.

Case 1. Poiseuille flow (cf. Fig. 1(a)]

We assume that the solid and fluid adhere to the boundary and that their profiles are symmetric about the mid-plane as gravity effects are neglected. Thus,

$$
\begin{gathered}
u_{\mathrm{s}}( \pm h)=0, \\
u_{\mathrm{f}}( \pm h)=0, \\
u_{\mathrm{s}}(+y)=u_{\mathrm{s}}(-y), \\
u_{\mathrm{f}}(+y)=u_{\mathrm{f}}(-y) .
\end{gathered}
$$

Equation $(60)_{3}$ implies that (52) has to be an even function, $\dagger$ and thus

$$
c_{1}=c_{2} \text { and } c_{4}=0 \text {. }
$$

Using the adherence boundary conditions $(60)_{1,2}$ we get

$$
c_{1}=\frac{-k_{1}}{\left(\mu_{\mathrm{f}}+\mu_{\mathrm{s}}\right)\left(\mathrm{e}^{m_{1} h}+\mathrm{e}^{-m_{1} h}\right)}
$$

and

$$
c_{5}=\frac{k_{1}}{\left(\mu_{\mathrm{f}}+\mu_{\mathrm{s}}\right)}\left\{\frac{1}{m_{1}^{2}}-\frac{h^{2}}{2}\right\}
$$

IIn a real problem it is possible that the electric field varies in the flow region, which would imply a flow field that is not necessarily symmetric about a mid-plane. In fact, in order to study the problem fully, we would have to solve for the electric field. However, here, we are using the electric field like a fixed parameter that enters the problems. Moreover, we note from (47) and (48) that all that is necessary for determining the solutions are boundary conditions $(60)_{1}$ and $(60)_{2}$. The assumptions $(60)_{3}$ and $(60)_{4}$ help in greatly simplifying the method of solution, and is not inconsistent with the other assumptions and physical expectation. 
Thus

$$
\begin{gathered}
u_{\mathrm{s}}=\frac{c_{1}}{m_{1}^{2}}\left(\mathrm{e}^{m_{1} y}+\mathrm{e}^{-m_{1} y}\right)+\frac{k_{1} y^{2}}{2\left(\mu_{\mathrm{f}}+\mu_{\mathrm{s}}\right)}+c_{5} \\
u_{\mathrm{f}}=-\frac{\mu_{\mathrm{s}}}{\gamma_{1}}\left\{c_{1}\left(\mathrm{e}^{m_{1} y}+\mathrm{e}^{-m_{1} y}\right)+\frac{k_{1}}{\mu_{\mathrm{f}}+\mu_{\mathrm{s}}}\right\}+\frac{c_{1}}{m_{1}^{2}}\left(\mathrm{e}^{m_{1} y}+\mathrm{e}^{-m_{1} y}\right)+\frac{k_{1} y^{2}}{2\left(\mu_{\mathrm{f}}+\mu_{\mathrm{s}}\right)}+c_{5} .
\end{gathered}
$$

Case II. Couette flow [cf. Fig. 1(b)]

We assume that the top plate moves with a speed $U$ along the $x$-direction and that the fluid and granular solid adhere to the boundary. Then the boundary conditions are

$$
\begin{aligned}
& u_{\mathrm{s}}(h)=U, \\
& u_{\mathrm{s}}\left(y^{*}\right)=0, \\
& u_{\mathrm{f}}(h)=U, \\
& u_{\mathrm{f}}\left(y^{*}\right)=0,
\end{aligned}
$$

where $y^{*}$ denotes the $y$-coordinate at which flow is initiated.

It follows from $(66)_{3},(52)$ and (53) that

$$
\begin{gathered}
c_{2}=\frac{k_{1}}{\left(\mu_{\mathrm{f}}+\mu_{\mathrm{s}}\right)} \frac{\left(\mathrm{e}^{-m_{1} h}-\mathrm{e}^{-m_{1} y^{*}}\right)}{\left(\mathrm{e}^{-2 m_{1} y^{*}}-\mathrm{e}^{-2 m_{1} h}\right)} \\
c_{1}=-\frac{k_{1} \mathrm{e}^{-m_{1} y^{*}}}{\left(\mu_{\mathrm{f}}+\mu_{\mathrm{s}}\right)}-c_{2} \mathrm{e}^{-2 m_{1} y^{*}} \\
c_{4}=\frac{U}{\left(h-y^{*}\right)}+\left\{\frac{c_{1}}{m_{1}^{2}}\left(\mathrm{e}^{m_{1} y^{*}}-\mathrm{e}^{m_{1} h}\right)+\frac{c_{2}}{m_{1}^{2}}\left(\mathrm{e}^{-m_{1} y^{*}}-\mathrm{e}^{-m_{\mathrm{l}} h}\right)+\frac{k_{1}}{2\left(\mu_{\mathrm{f}}+\mu_{\mathrm{s}}\right)}\left(y^{* 2}-h^{2}\right)\right\} /\left(h-y^{*}\right) \\
c_{5}=-\frac{c_{1}}{m_{1}^{2}} \mathrm{e}^{m_{1} y^{*}}-\frac{c_{2}}{m_{1}^{2}} \mathrm{e}^{-m_{1} y^{*}}-\frac{k_{1} y^{*^{2}}}{2\left(\mu_{\mathrm{f}}+\mu_{\mathrm{s}}\right)}-c_{4} y^{*} .
\end{gathered}
$$

Thus

$$
\begin{gathered}
u_{\mathrm{s}}=\frac{c_{1}}{m_{1}^{2}} \mathrm{e}^{m_{1} y}+\frac{c_{2}}{m_{1}^{2}} \mathrm{e}^{-m_{1} y}+\frac{k_{1} y^{2}}{2\left(\mu_{\mathrm{f}}+\mu_{\mathrm{s}}\right)}+c_{4} y+c_{5} \\
u_{\mathrm{f}}=\frac{-\mu_{\mathrm{s}}}{\gamma_{1}}\left\{c_{1} \mathrm{e}^{m_{1} y}+c_{2} \mathrm{e}^{-m_{1} y}+\frac{k_{1}}{\left(\mu_{\mathrm{f}}+\mu_{\mathrm{s}}\right)}\right\}+\frac{c_{1}}{m_{1}^{2}} \mathrm{e}^{m_{1} y}+\frac{c_{2}}{m_{1}^{2}} \mathrm{e}^{-m_{1} y}+\frac{k_{1} y^{2}}{2\left(\mu_{\mathrm{f}}+\mu_{\mathrm{s}}\right)}+c_{4} y+c_{5} .
\end{gathered}
$$

The mixture velocity $\left(u_{\mathrm{m}}\right)$ and mixture viscosity $\left(\mu_{\mathrm{m}}\right)$ are computed using (55) and (57), respectively.

Table 1 shows the values of $\sigma_{0}, k_{1}, \gamma_{1}, \mu_{\mathrm{s}}, \mu_{\mathrm{f}}, \rho^{\mathrm{s}}, \rho^{\mathrm{f}}$ used to generate the velocity profiles for Poiseuille flow and Table 2 shows the values of $\sigma_{0}, k_{1}, u, \gamma_{1}, \mu_{\mathrm{s}}, \mu_{\mathrm{f}}, \rho^{\mathrm{s}}, \rho^{\mathrm{f}}$ used in Couette flow.

Table 1

\begin{tabular}{cccccc}
\hline $\begin{array}{c}\sigma_{0} \\
(\mathrm{~Pa})\end{array}$ & $\begin{array}{c}k_{1} \\
(\mathrm{~Pa} / \mathrm{m})\end{array}$ & $\begin{array}{c}\gamma_{1} \\
(\mathrm{~kg} / \mathrm{s})\end{array}$ & $\begin{array}{c}\mu_{\mathrm{r}} \\
(\mathrm{kg} / \mathrm{ms})\end{array}$ & $\begin{array}{c}\rho^{\mathrm{f}} \\
\left(\mathrm{kg} / \mathrm{m}^{3}\right)\end{array}$ & $\begin{array}{c}Y^{*} \\
(\mathrm{~m})\end{array}$ \\
\hline 8 & -64 & 0.1 & 0.1334 & 891.2 & 0.125 \\
& & 1 & & & \\
4 & -64 & 10 & & & \\
2 & -64 & 1 & 0.1334 & 891.2 & 0.0625 \\
0 & -64 & 1 & 0.1334 & 891.2 & 0.03125 \\
& & & \\
Note: $\mu_{\mathrm{s}}=1.5 \mu_{\mathrm{f}}, \rho^{\mathrm{s}}=3.5 \rho^{\mathrm{r}}$.
\end{tabular}


Table 2

\begin{tabular}{cccccccc}
\hline $\begin{array}{c}\sigma_{0} \\
(\mathrm{~Pa})\end{array}$ & $\begin{array}{c}k_{1} \\
(\mathrm{~Pa} / \mathrm{m})\end{array}$ & $\begin{array}{c}\gamma_{1} \\
(\mathrm{~kg} / \mathrm{s})\end{array}$ & $\begin{array}{c}\mu_{\mathrm{r}} \\
(\mathrm{kg} / \mathrm{ms})\end{array}$ & $\begin{array}{c}\rho^{\mathrm{r}} \\
\left(\mathrm{kg} / \mathrm{m}^{3}\right)\end{array}$ & $\begin{array}{c}U \\
(\mathrm{~m} / \mathrm{s})\end{array}$ & $\begin{array}{c}Y^{*} \\
(\mathrm{~m})\end{array}$ \\
\hline 16 & -64 & 0.1 & 0.1334 & 891.2 & 10 & 0.34169 \\
& & 1 & & & & \\
8 & -64 & 10 & & & & & \\
4 & -64 & 1 & 0.1334 & 891.2 & 10 & 0.13018 \\
4 & -64 & 1 & 0.1334 & 891.2 & 10 & 0.01879 \\
4 & -64 & 1 & 0.1334 & 891.2 & 100 & 0.0 \\
\hline
\end{tabular}

Note: $\mu_{\mathrm{s}}=1.5 \mu_{\mathrm{f}}, \rho^{\mathrm{s}}=3.5 \rho^{\mathrm{f}}$.

In the case of Poiseuille flow, Figs 2-4 illustrate the effect of increasing the electric field, which results in an increase in the yield stress. As expected, increasing the yield stress increases the plug region. Figure 2 corresponds to the classical Poiseuille flow in the absence of the electric field. The velocity of the solid, fluid and mixture have been normalized with respect to the maximum fluid velocity. Figures 4,5 and 6 show the effect on the velocity profiles due to a variation in the interaction parameter $\gamma_{1}$ which is akin to Stokes drag on a particle. It may be noticed that changes in $\gamma_{1}$ neither enhance nor diminish the plug flow domain, but as we would expect it affects the difference in velocities between the solid and the fluid. As $\gamma_{1}$, increases the difference between the speeds of the fluid and solid increases. Notice that the mixture velocity always lies within those of the solid and fluid.

In the case of the flow between flat plates with the top plate moving, and in the presence of a pressure gradient, we observe that an increase in the yield stress $\left(\sigma_{0}\right)$ increases the plug region

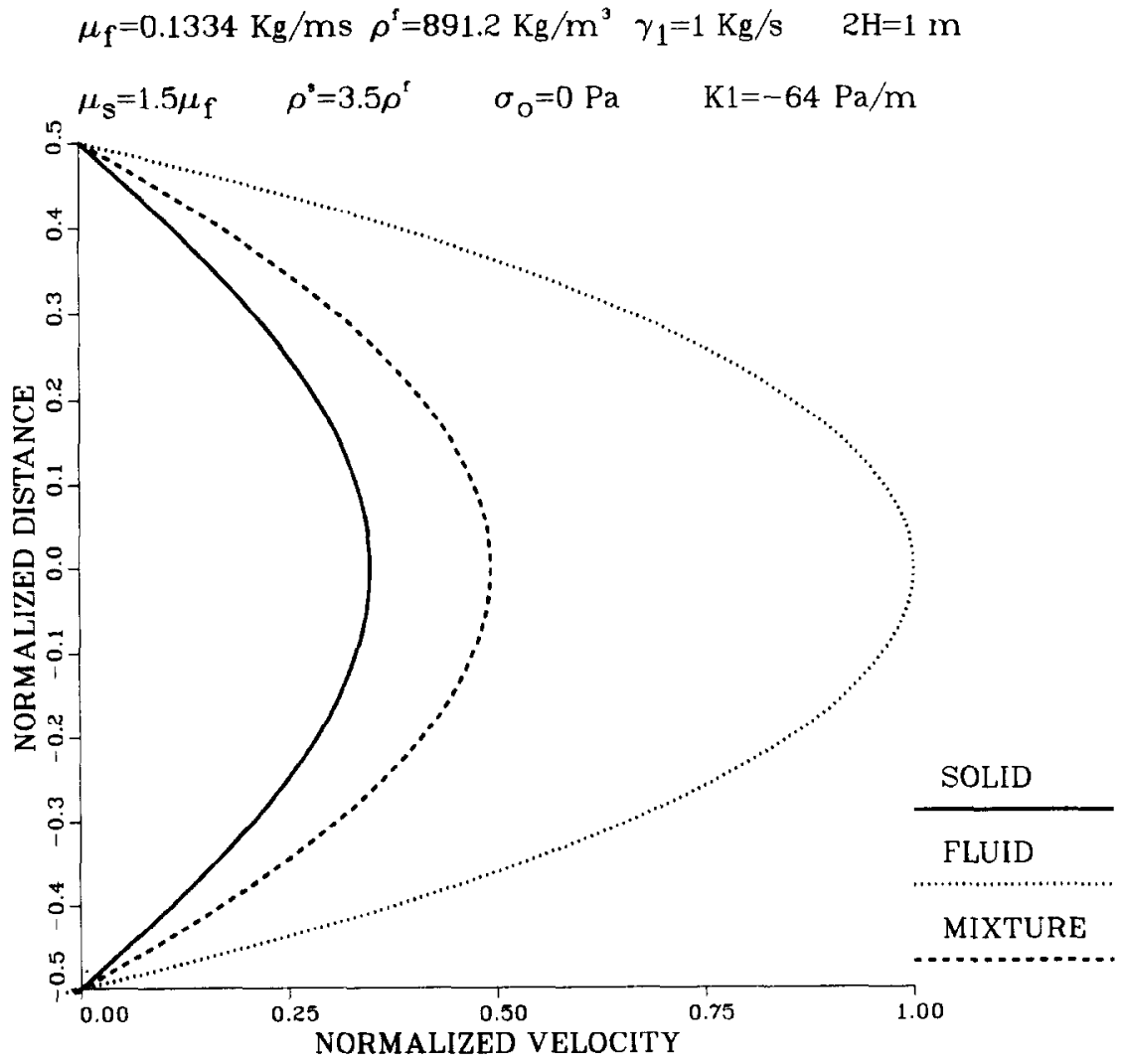

Fig. 2. Normalized velocity vs normalized distance (Poiseuille flow-no electric field). 


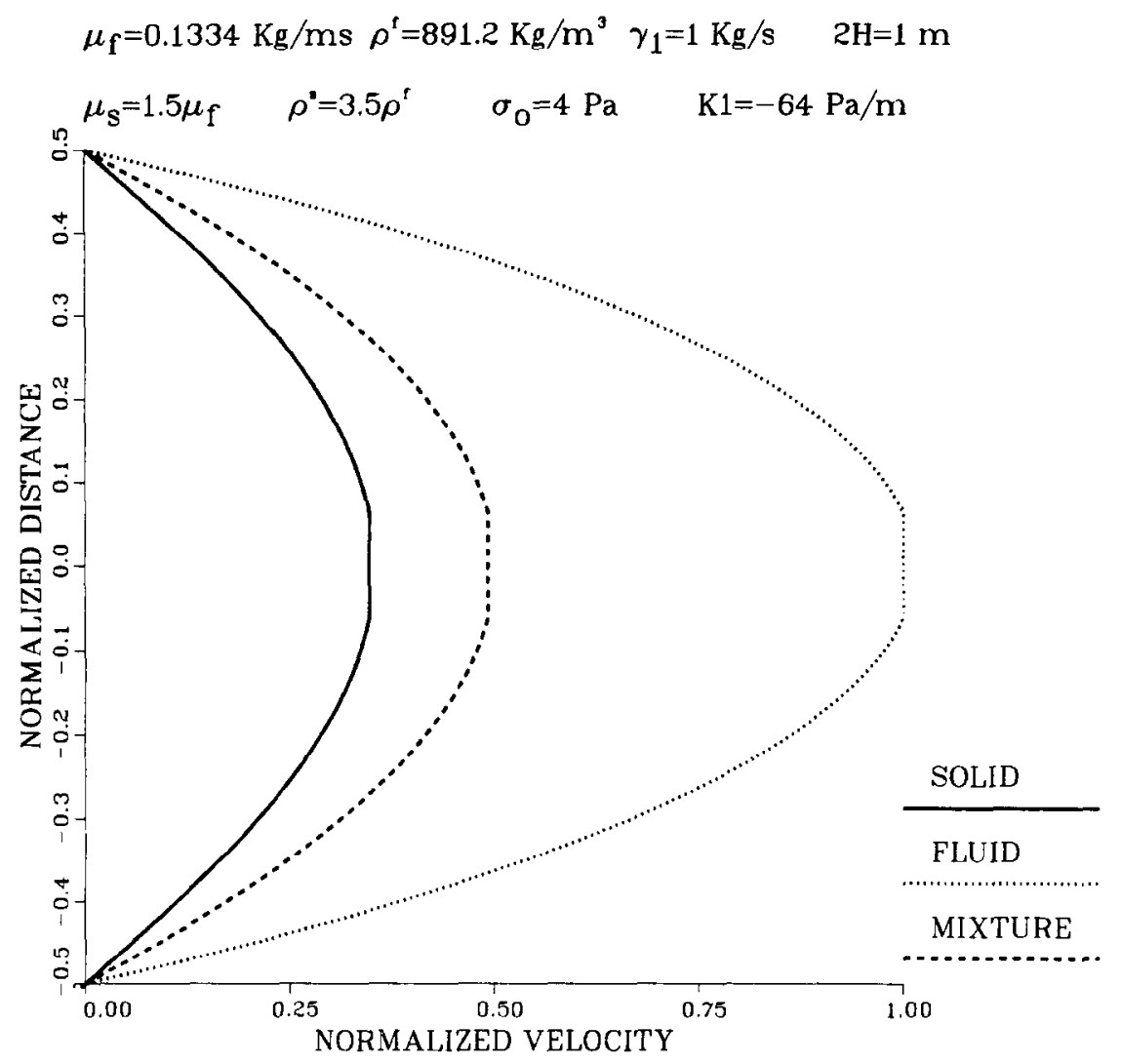

Fig. 3. Normalized velocity vs normalized distance (Poiseuille flow-with electric field).

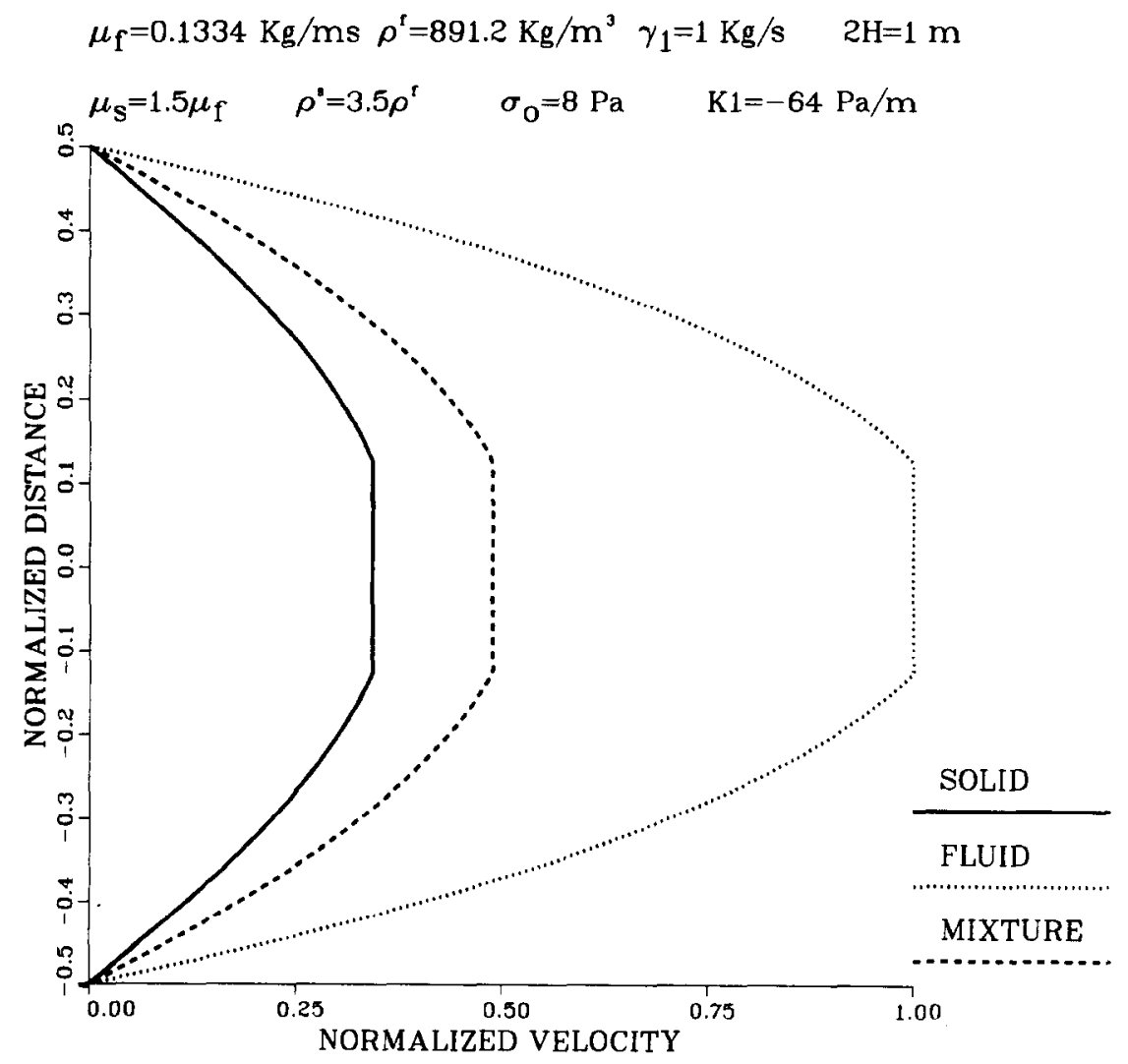

Fig. 4. Normalized velocity vs normalized distance (Poiseuille flow). 


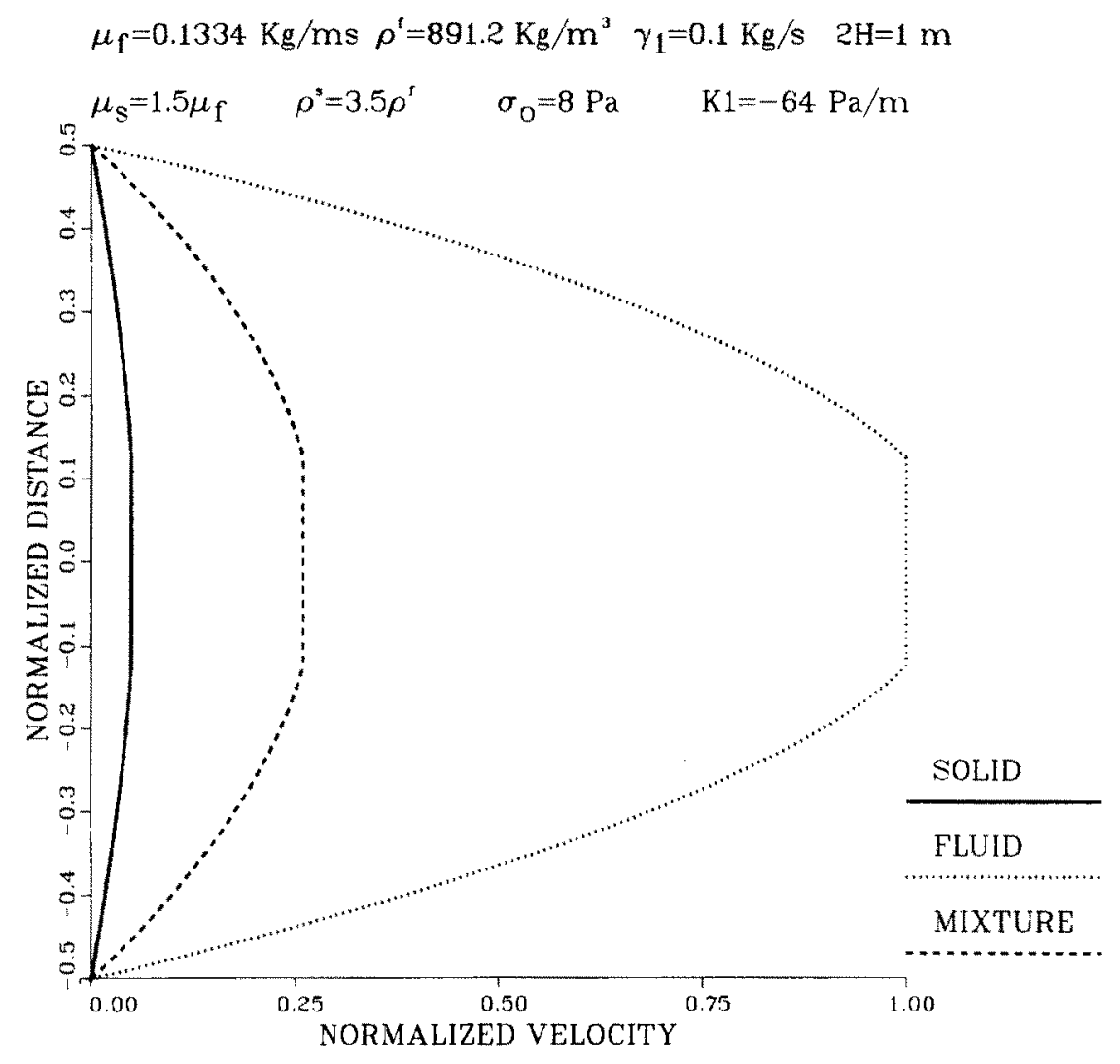

Fig. 5. Normalized velocity vs normalized distance (Poiseuille flow).

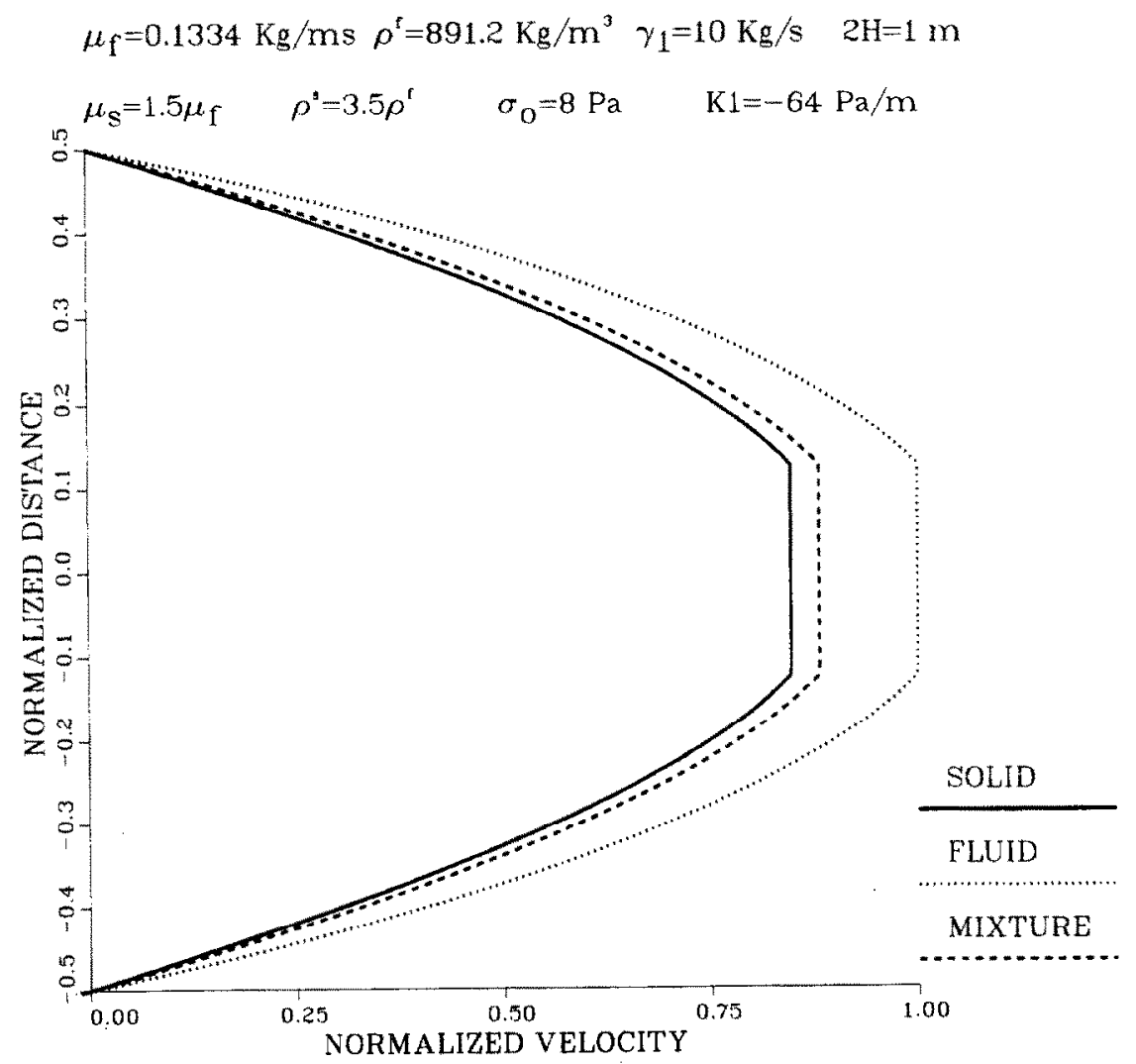

Fig. 6. Normalized velocity vs normalized distance (Poiseuille flow). 


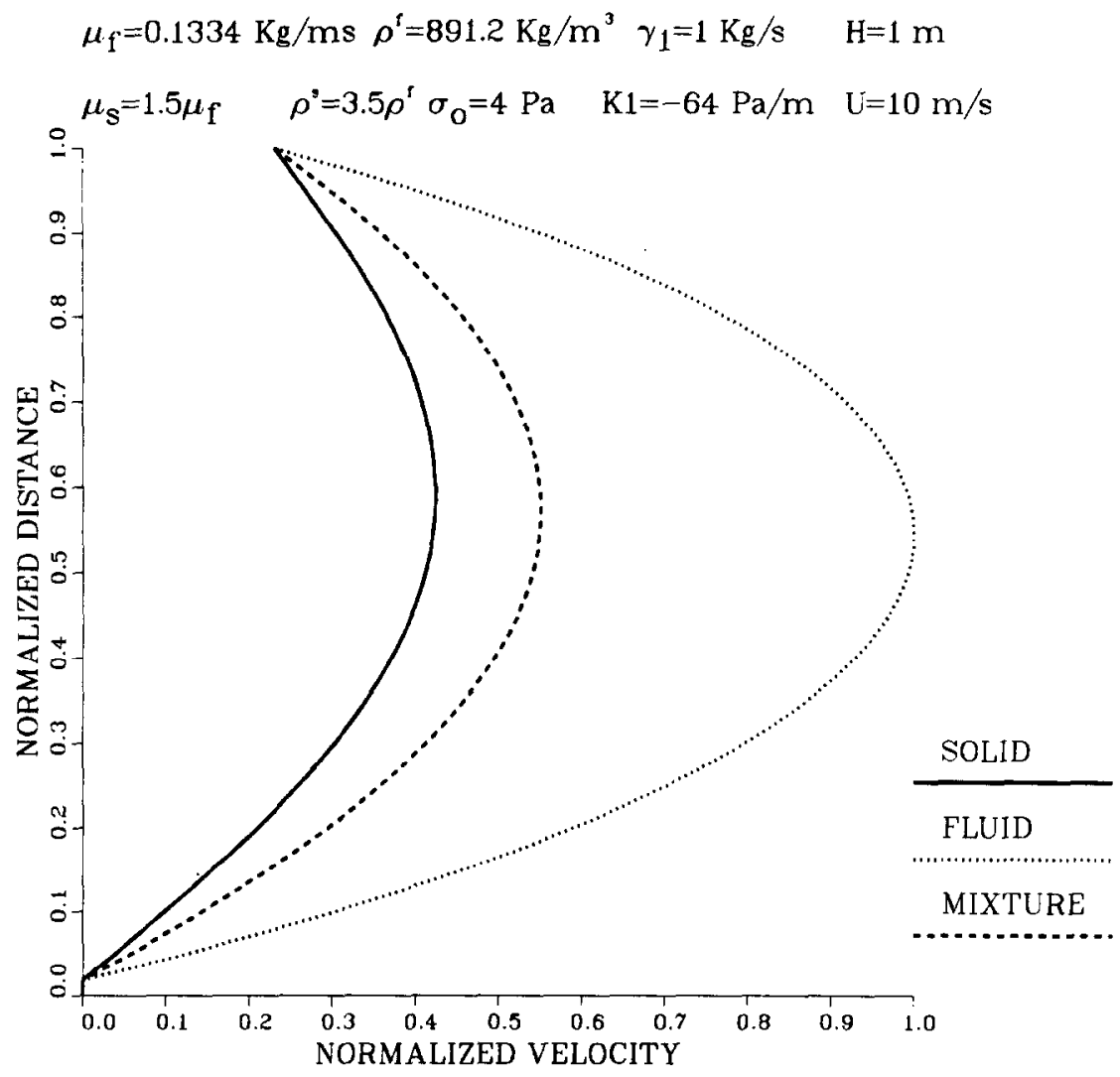

Fig. 7. Normalized velocity vs normalized distance (Couette flow).

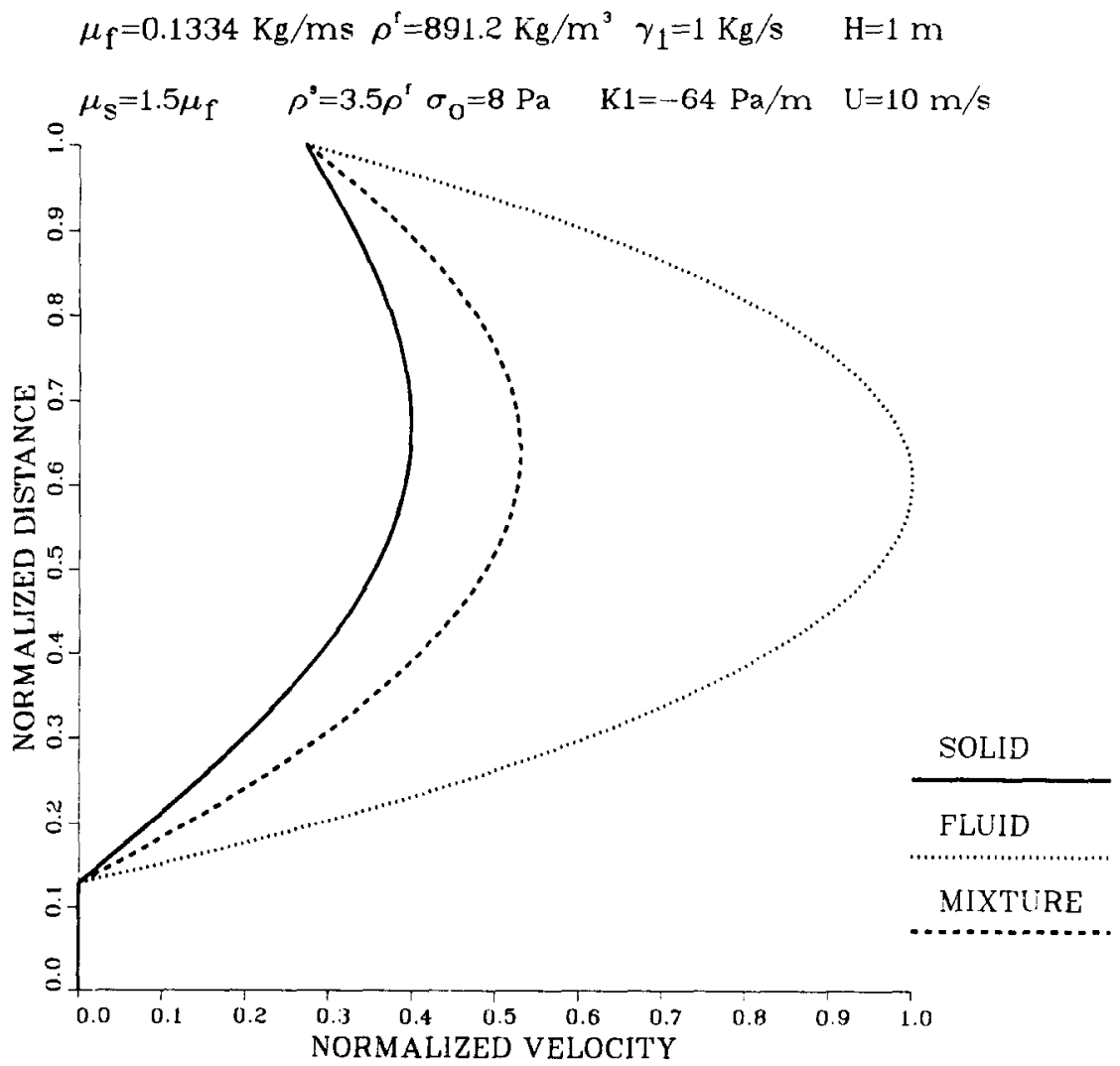

Fig. 8. Normalized velocity vs normalized distance (Couette flow). 


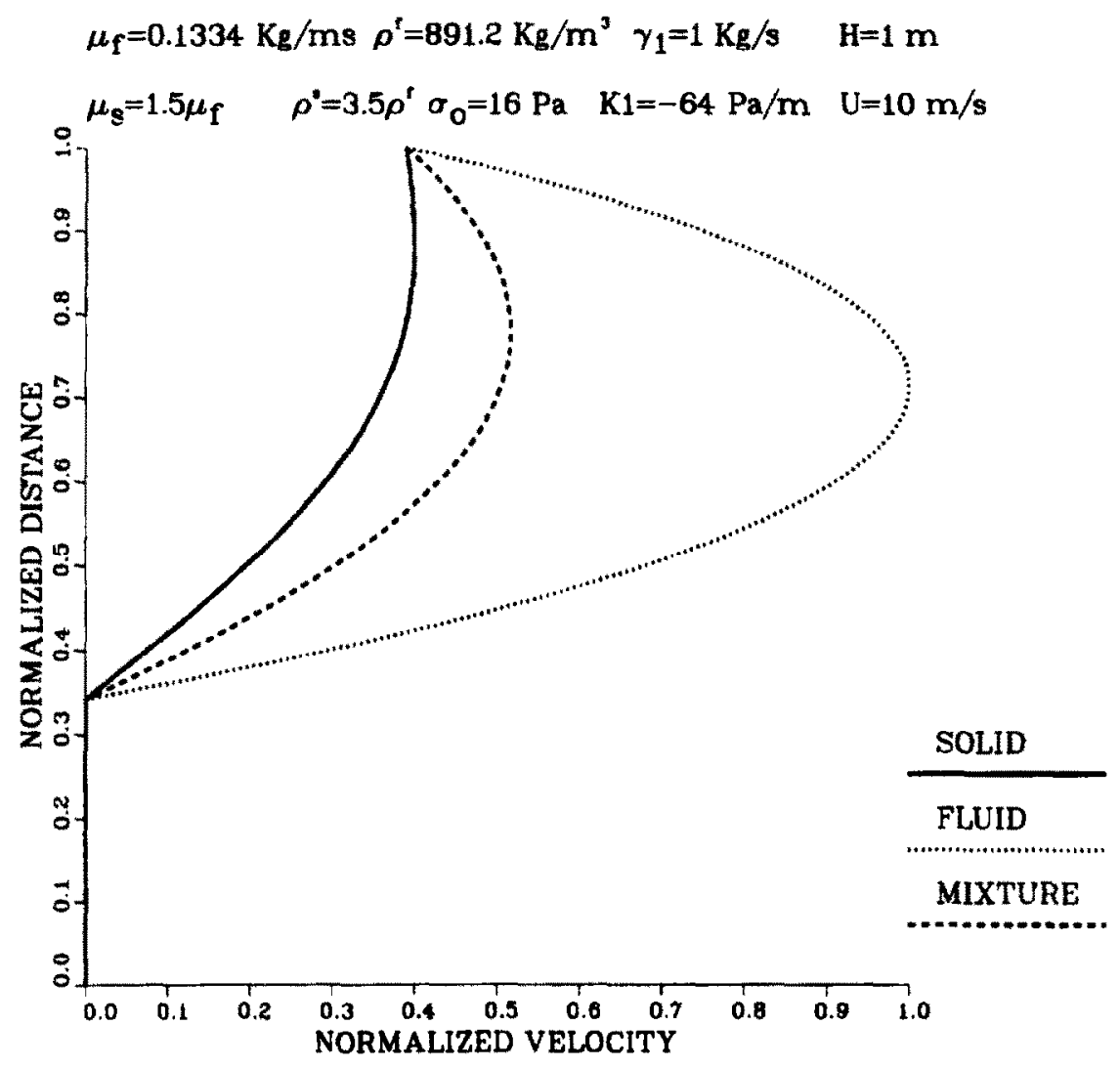

Fig. 9. Normalized velocity vs normalized distance (Couette flow).

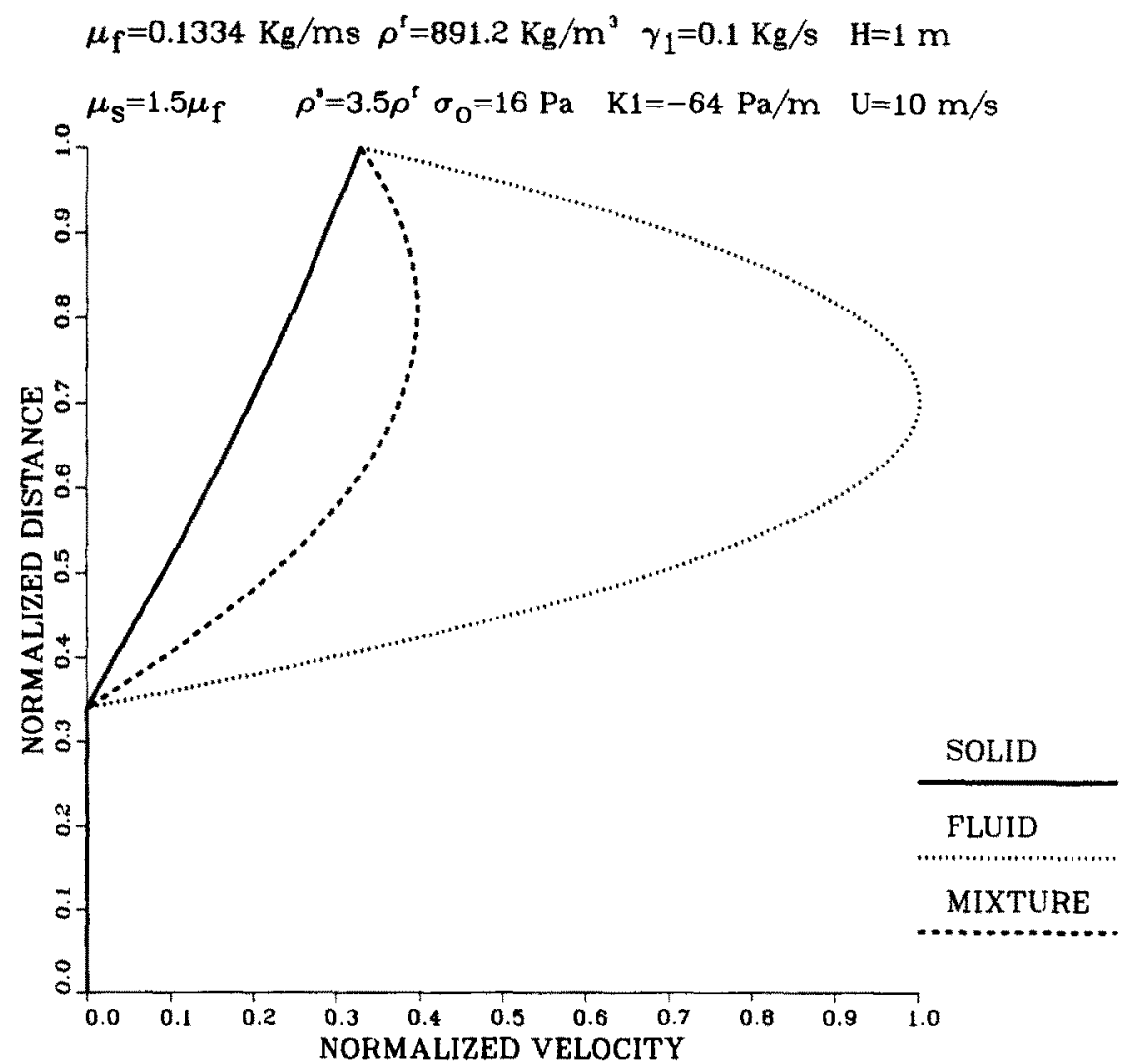

Fig. 10. Normalized velocity vs normalized distance (Couette flow). 


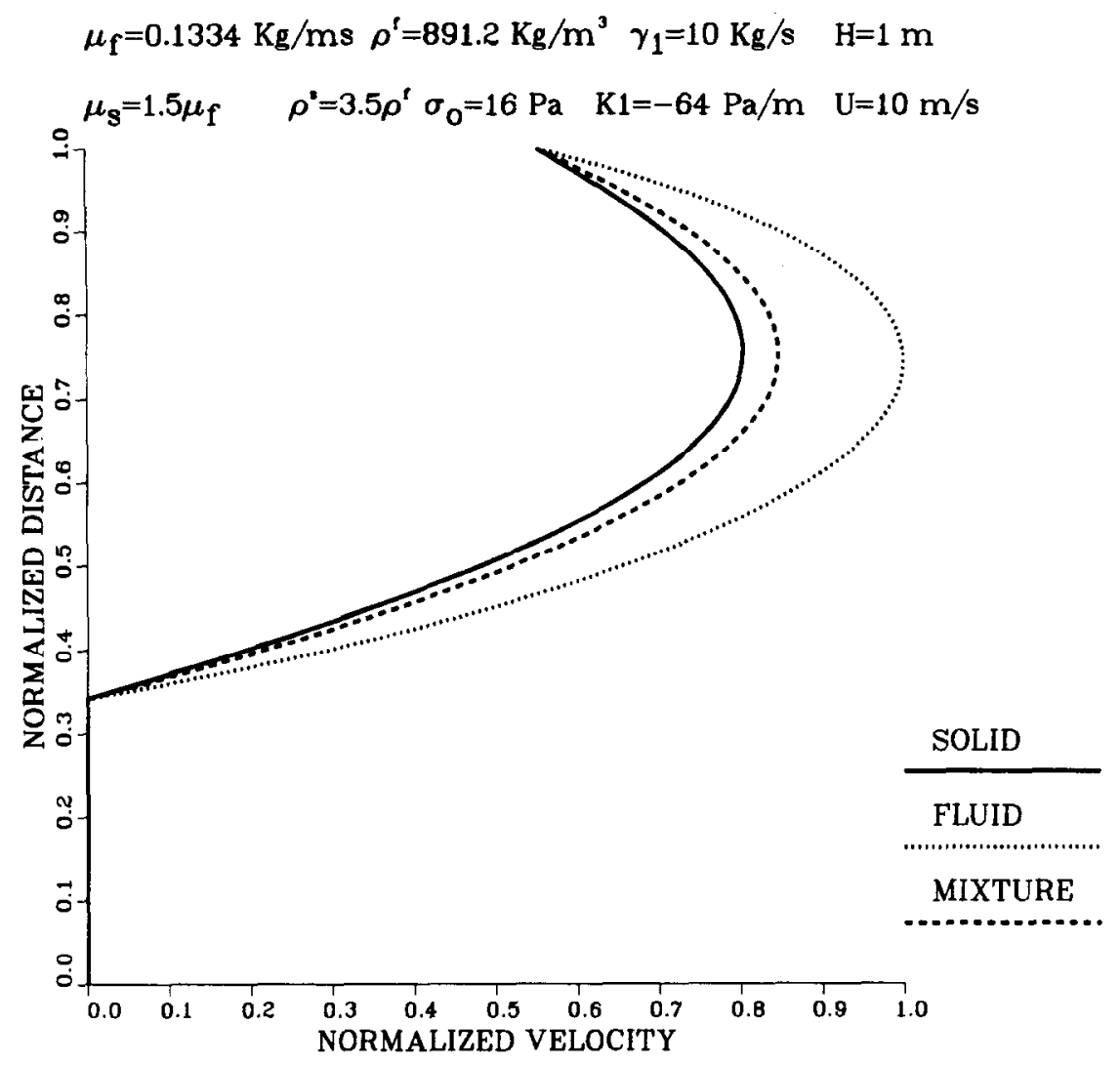

Fig. 11. Normalized velocity vs normalized distance (Couette flow).

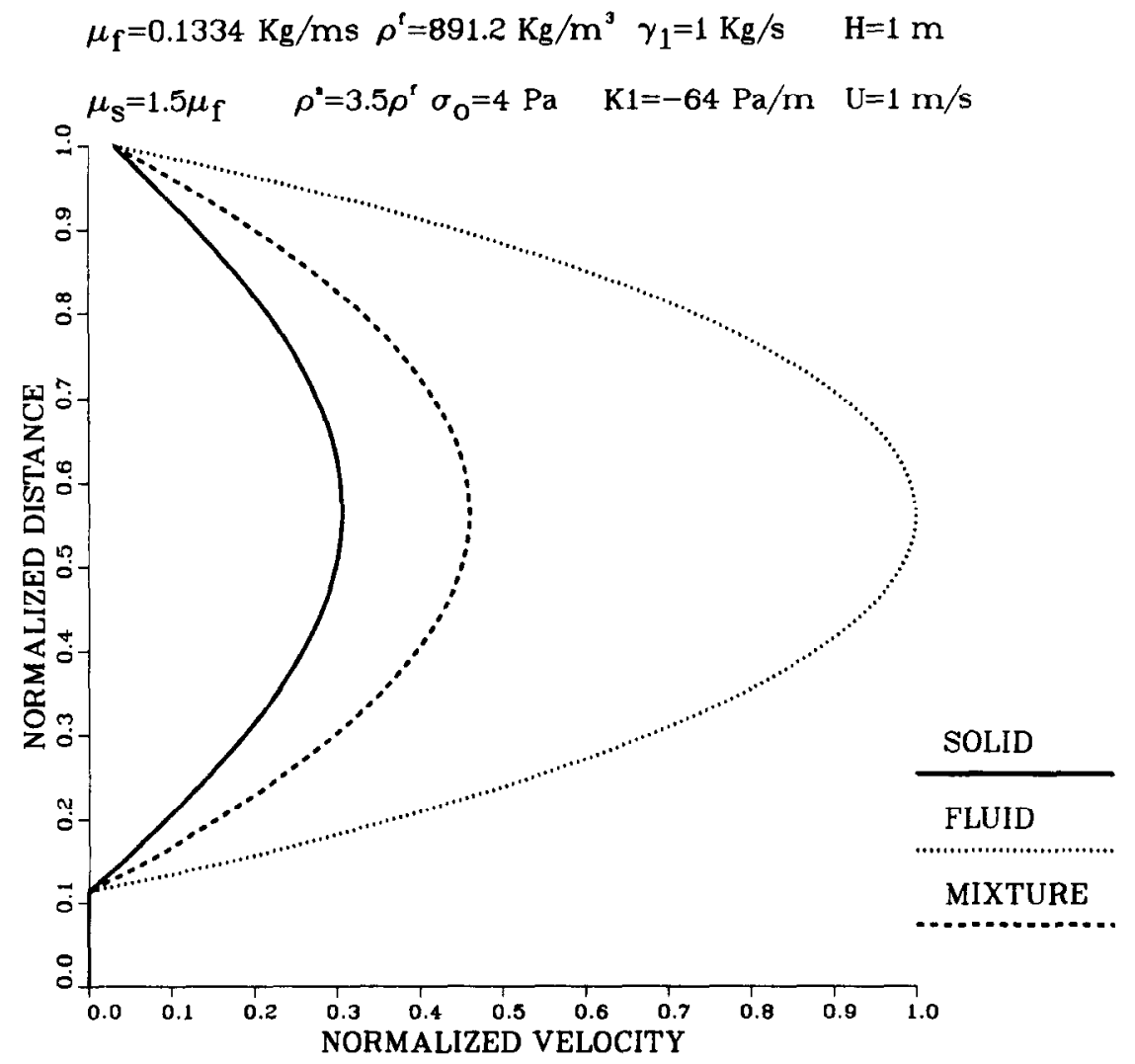

Fig. 12. Normalized velocity vs normalized distance (Couette flow). 


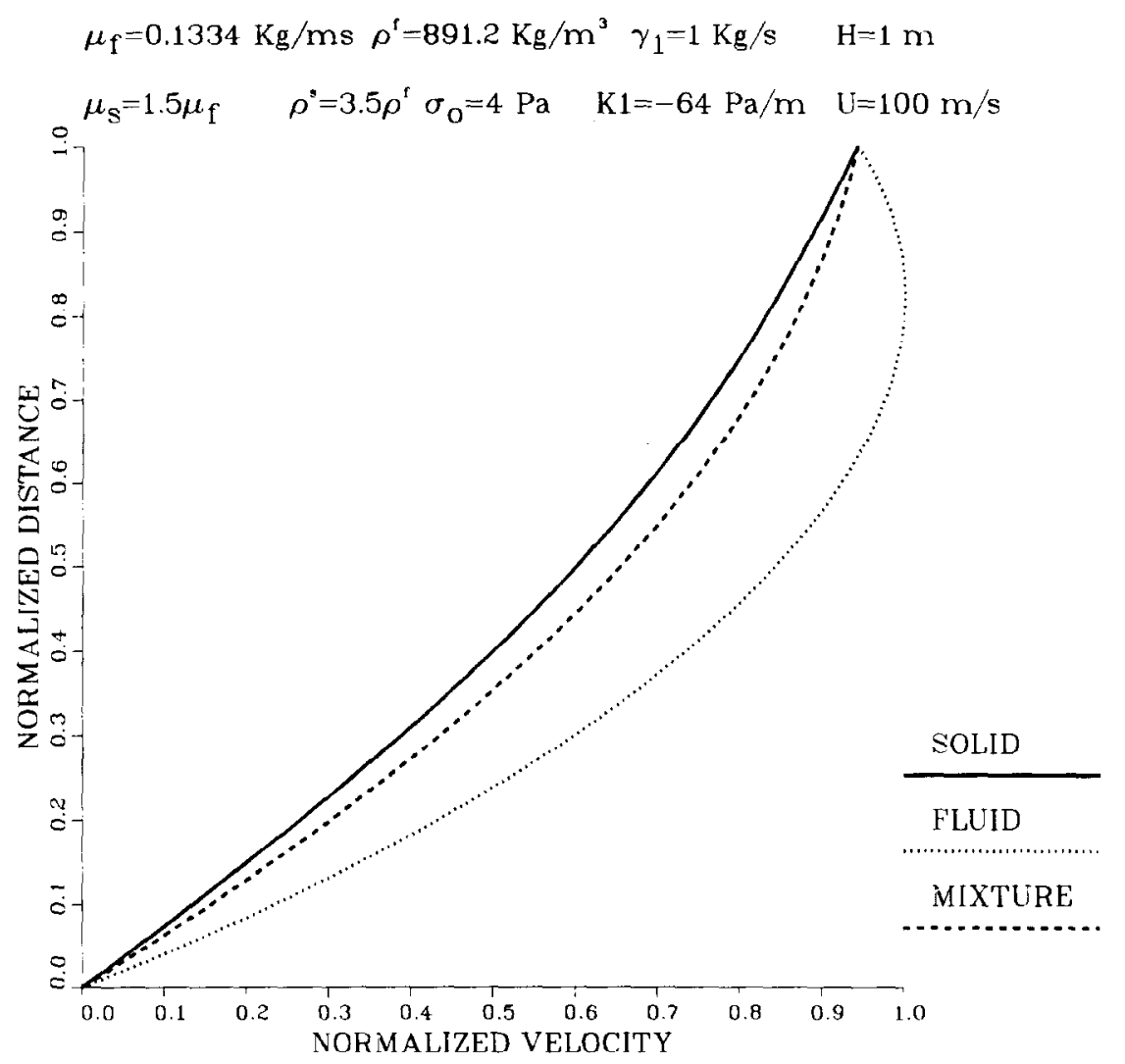

Fig. 13. Normalized velocity vs normalized distance (Couette flow).

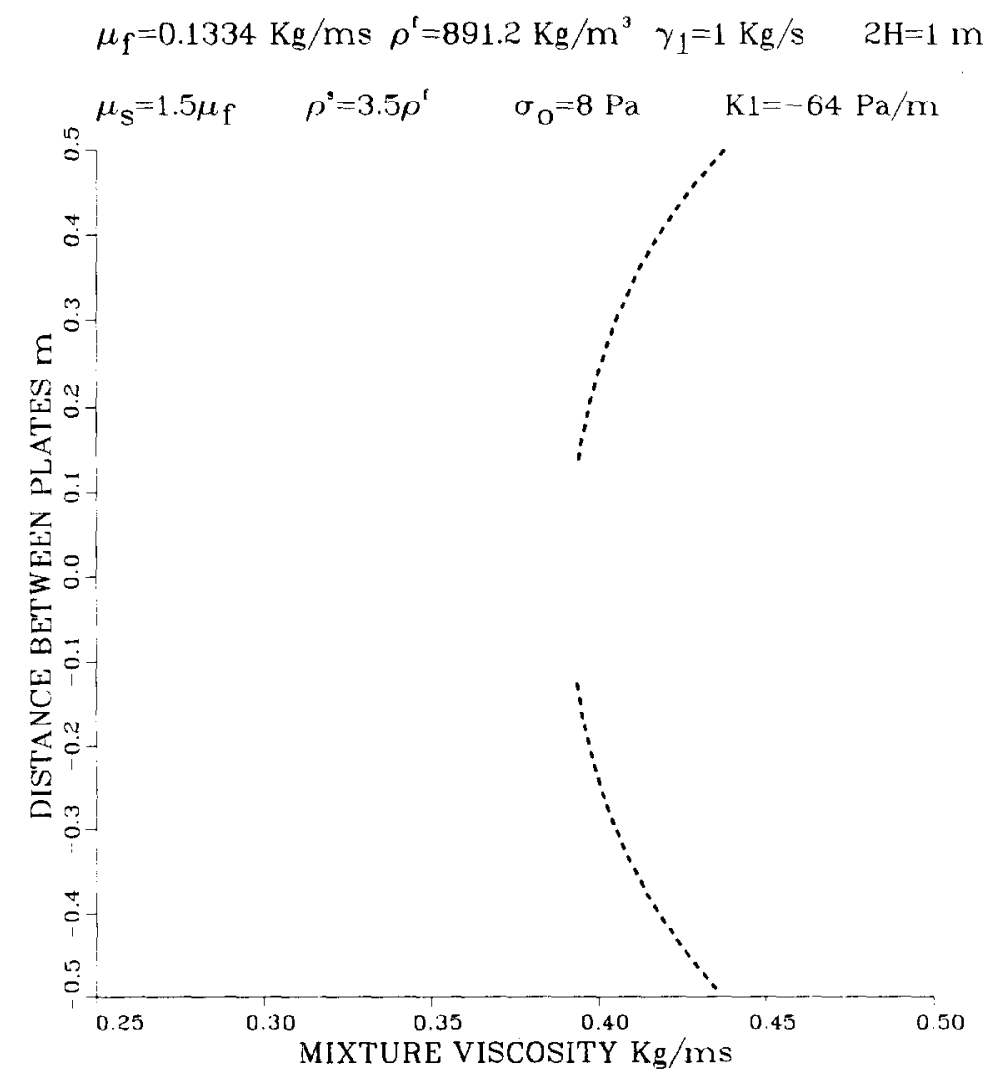

Fig. 14. Normalized velocity vs normalized distance between plates (Poiseuille flow). 


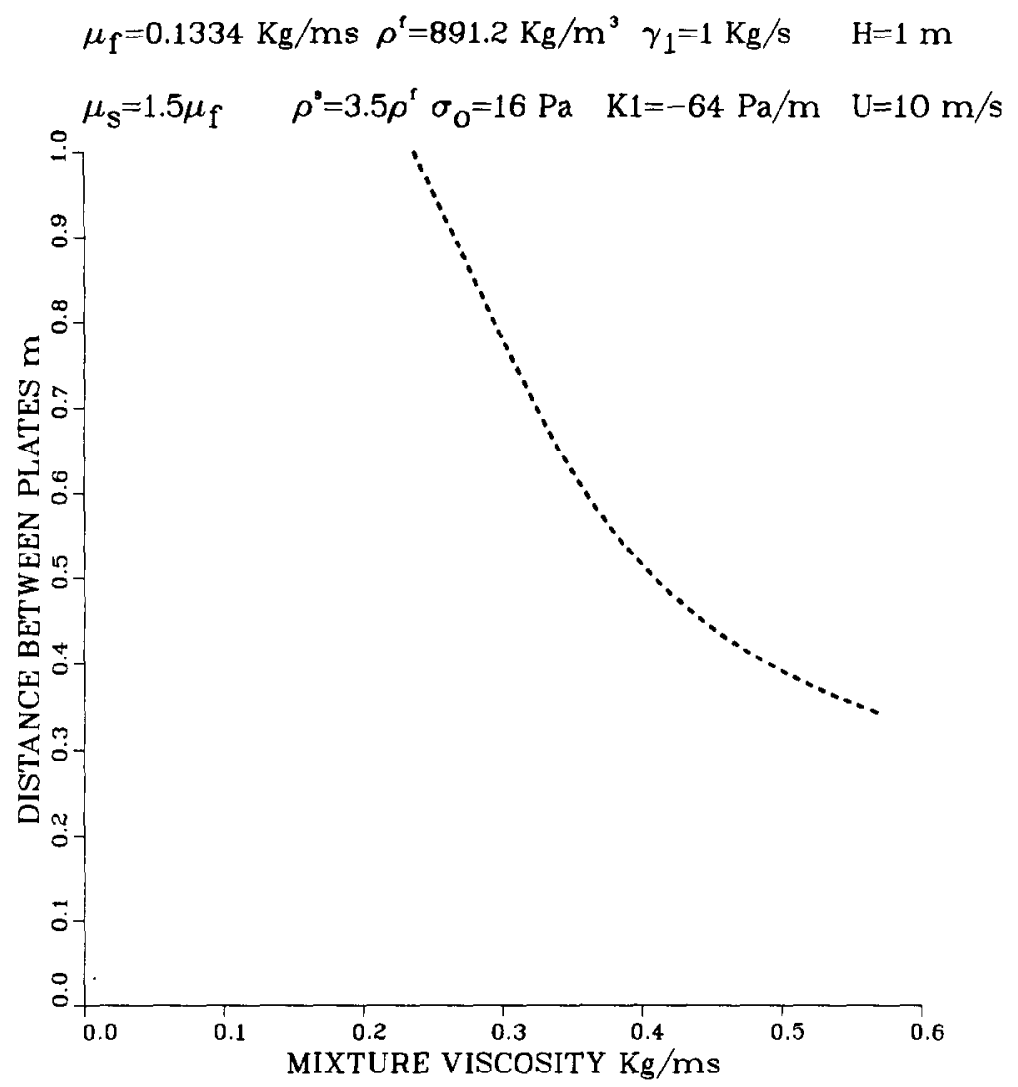

Fig. 15. Mixture velocity vs distance between plates (Couette flow).

(Figs 7-9), similar to that observed in the case of Poiseuille flow. However, unlike the problem of Poiseuille flow the plug region is not symmetrically placed with respect to the flow field, but is adjacent to the fixed bottom plate. Of course, increasing the pressure gradient and the plate velocity such that the shear stress is larger than the yield stress would eliminate the plug region altogether. On increasing the interaction parameter $\gamma_{1}$, the region of zero velocity does not change (Figs 9-11), but the difference between normalized velocities of the solid and fluid decreases. Figures 7,12 and 13 illustrate the effect of changing the velocity of the top plate. Increasing the velocity of the top plate decreases the region of zero velocity (plug region) and this is to be expected as the shear stresses in the flow domain is higher than in the case with lower top plate velocity.

In both the cases considered, the solid and fluid viscosities are taken as constants, but as illustrated in Figs 14 and 15, it is observed that the mixture viscosity as defined through (57) changes with position. The fact that the differcnce between the fluid and solid velocities and their respective velocity gradients change with position induces the mixture viscosity as defined through (57) to change with position.

The above solutions are in complete agreement with the predictions of the homogenized single continuum theory of Rajagopal and Wineman [2] in that there is a central region in which there is plug flow, for the mixture. 


\section{REFERENCES}

[1] W. M. WINSLOW, J. Appl. Phys. 20, 1137 (1949).

2] K. R. RAJAGOPAL and A. S. WINEMAN, Acta Mech. 91, 57 (1992).

[3] C. TRUESDELL, Rend. Lincei Ser 8 22, 33 (1957).

[4] C. TRUESDELL, Rational Thermodynamics, 2nd edn. Springer, Berlin (1984).

[5] M. MASSOUDI, Int. J. Engng Sci 26, 765 (1988).

[6] G. JOHNSON, M. MASSOUDI and K. R. RAJAGOPAL, Chem. Engng Sci. 46, 1713 (1991).

[7] G. JOHNSON, M. MASSOUDI and K. R. RAJAGOPAL, Int. J. Engng Sci. 29, 649 (1991).

[8] J. E. ADKINS, Phil. Trans. R. Soc. 225A, 607 (1963).

[9] C. TRUESDELL, A First Course in Rational Continuum Mechanics, Vol. 1. Academic Press, New York.

[10] A. J. M. SPENCER, Theory of invariants. In Continuum Physics (Edited by A. C. ERINGEN). Academic Press, New York (1974).

[11] G. JOHNSON, M. MASSOUDI and K. R. RAJAGOPAL, A review of interaction mechanisms in fluid-solid flows. Topical Report, DOE/PETC-TR-90-9 (1990).

[12] K. R. RAJAGOPAL, A. S. WINEMAN and M. GANDHI, Int. J. Engng $S_{c i .}$ 24, 1453 (1986).

[13] K. R. RAJAGOPAL and M. MASSOUDI, A method for measuring the material moduli of granular materials: flow in an orthogonal rheometer. Topical Report, DOE/PETC/TR-90/3.

(Received 2 February 1993; accepted 14 April 1993) 